\section{Resúmenes del VII Congreso Paraguayo de Neumología (Luque-Paraguay, noviembre, 2014)*}

1

Síndrome antisintetasa y compromiso pulmonar: Casuística

Baumann K, Rojas E, Ojeda A, Acosta I, Yinde Y, Duarte M

Servicio Reumatología-Hospital Clínicas-FCMUNA

Introducción: El síndrome antisintetasa (SAS) es una patología poco frecuente, se caracteriza por la asociación de enfermedad pulmonar intersticial, clínica inflamatoria sistémica, miosistis, artritis, fenómeno de Raynaud, manos de mecánico, en presencia de anticuerpos antisintetasa, principalmente anti-Jo1. A continuación se describen cuatro casos del servicio del presente año. Descripción de casos: Paciente 1: Varón de 27 años, auxiliar contable, portador de enfermedad celíaca, evaluado por presentar debilidad muscular de ocho días de evolución, tos en ocasiones con estrías de sangre, antecedentes de dolor y tumefacción articular de seis meses de evolución. En la exploración física destacaba fuerza muscular ligeramente disminuida en MMII. Desde el punto de vista analítico, resaltaba la presencia de ANA positivos, con anticuerpos anti-Jo1 positivos, CPK muy elevada. En la TACAR tórax se evidenciaban tractos de fibrosis basal, y en vértice derecho imagen sugerente a caverna. En función de estos hallazgos se estableció el diagnóstico de SAS y por compatibilidad clínico-radiológica, aunque con baciloscopia negativa, se inicio tratamiento primero antibacilar y luego de un mes, tratamiento inmunosupresor con azatioprina por SAS. La evolución del paciente ha sido satisfactoria, manteniéndose asintomático y con la imagen en vértice derecho con aspecto fibrótico, no activa, en curación. Paciente 2: Mujer de 31 años, dedicada a las labores domésticas, sin patología de base previa, presenta cuadro de dos meses de dolor y tumefacción articular, al que se agregan quince días antes de la consulta dolor y debilidad muscular sin otro síntoma acompañante. En la exploración se objetivó artritis en interfalángicas proximales, dolor y ligera debilidad muscular en MMII. En la analítica llamaba la atención CPK elevada en presencia de ANA negativo y anti-Jo 1 positivo. En la TACAR tórax se confirmó la presencia de múltiples trazos fibróticos a nivel basal posterior izquierdo. Con estos datos se estableció el diagnóstico de SAS y se comenzó tratamiento con corticoides e inmunosupresor (azatioprina). Posteriormente, la paciente permaneció asintomática, actualmente ya sin corticoides con buena evolución. Paciente 3: Mujer de 36 años, médica, con antecedente de artritis, miositis, afectación pulmonar con perfil reumatológico negativo, estuvo en tratamiento con azatioprina por dos años. Consultó actualmente por cuadro de dos meses de evolución de disnea, tos seca, rigidez matutina, debilidad muscular en hombros. Al examen físico llamaba la atención

\footnotetext{
* La transcripción de los resúmenes es responsabilidad de la Sociedad Paraguaya de Neumología,
} así como la numeración.

fuerza muscular disminuida a nivel de la cintura escapular, artritis en manos y rodillas, murmullo vesicular disminuido en bases y fenómeno de Raynaud en manos. En la analítica laboratorial resaltó VSG, CPK muy elevadas, se solicita anti-Jo1 por sospecha de SAS, el cual retorna muy positivo. En la TACAR de tórax llamó la atención infiltrado intersticial en bases con espirometría sugerente de restricción pulmonar y DLCO dentro de límites normales. La paciente inició recientemente su primer bolo de ciclofosfamida, a evaluar evolución. Paciente 4: Varón de 48 años, no conocido portador de patología de base, consultó por dolor y debilidad de MMII y MMSS, disnea progresiva. Al examen físico fuerza muscular disminuida en miembros, murmullo vesicular disminuido en base izquierda. Entre los datos de laboratorio resaltaron enzimas musculares y aldolasa elevadas, anti-RO positivo y anti-JO 1 positivo. La TACAR de tórax reveló un patrón en vidrio esmerilado. El paciente recibió durante su internación bolos de metil prednisolona y ciclofosfamida y continuó con ciclofosfamida mensual. Actualmente se realizó el 6to. bolo de ciclofosfamida y se encuentra asintomático. Conclusión: El síndrome antisintetasa es una entidad asociada a las miopatías inflamatorias. La enfermedad pulmonar intersticial es el rasgo clínico característico y se manifiesta como tos seca y disnea de esfuerzo, aunque no siempre están presentes. En ocasiones la miositis puede aparecer años después de la afectación pulmonar. El anticuerpo anti-Jo1 es el más frecuentemente encontrado en estos pacientes, y parece estar relacionado con la aparición y la gravedad de la enfermedad pulmonar. Por lo tanto, es importante tener presente esta patología al momento de la consulta para un diagnóstico y tratamiento oportuno evitando así la progresión a la fibrosis pulmonar. 
2

\section{Paciente con artralgias, disnea y eritema nodoso}

\section{Baumann K, Rojas E, Acosta I,} Montaner S, Duarte M

Servicio Reumatología-Hospital ClínicasFCMUNA

Introducción: La sarcoidosis es una enfermedad sistémica, inflamatoria, granulomatosa de causa no conocida que se presenta generalmente entre los 20 y los 40 años. Esta patología tiene manifestaciones endotórcicas, cutáneas, oculares, musculares, articulares y pulmonares. En cuanto a esta última, puede cursar con un cuadro clínico de dolor torácico, disnea y tos, con presencia en la radiografía de tórax de adenopatías mediastínicas o un patrón intersticial, cuyo diagnóstico se establece mediante la demostración histológica de granulomas no caseificantes tras excluir otras causas. Presentación del caso: Paciente de 29 años de edad, sin patología de base previa, que presentó cuadro de seis meses de evolución de dolor, tumefacción articular de pequeñas y grandes articulaciones, disnea a moderados esfuerzos y lesiones en piel según refiere compatibles con eritema nodoso. $\mathrm{Al}$ examen físico no presentaba datos de valor. Se le solicitaron estudios complementarios. El perfil reumatológico resultó negativo, aunque la VSG estaba elevada. En la Rx de tórax se evidenció ensanchamiento mediastinal, la TACAR de tórax informó múltiples adenomegalias a nivel mediastinal y en lóbulos inferiores opacidad en vidrio esmerilado de distribución casi simétrica compatible con intersticiopatía. Se realizó evaluación funcional respiratoria donde se constató leve disminución de la capacidad de difusión de monóxido de carbono (DLCO), $75.0 \%$ (VR > 80\%) y la espirometría se mantuvo dentro de límites normales. Se le solicitó dosaje de enzima convertidora de la angiotensina, la cual retornó aumentada. Se realizó FBC con biopsia transbronquial en el Servicio de Neumología. El frotis y cultivo para gérmenes comunes hongos y BAAR resultó negativo. En la biopsia se constató proceso inflamatorio crónico granulomatoso no necrotizante, con lo que se concluyó con el diagnóstico de sarcoidosis. Conclusión: La sarcoidosis es una patología poco frecuente, en la cual en el $90 \%$ de los casos hay compromiso pulmonar y un $15 \%$ de éstos evolucionan a fibrosis. La manifestación cutánea más frecuente es el eritema nodoso. Por tanto, ante un paciente con artralgias, disnea y eritema nodoso, se debería pensar, luego de descartar otras causas, en sarcoidosis.

\section{3}

\section{Compromiso pulmonar en la artritis reumatoide}

\section{Coronel R, Otazu F, Cartes G, Maldonado L, Pérez D}

Dpto. Docencia INERAM

Introducción: La artritis reumatoide (AR) es la entidad más común entre las enfermedades del tejido conjuntivo. Se estima que el 50\% desarrollará compromiso respiratorio de forma variable y que podría ser la causa principal de mortalidad en hasta $20 \%$ de los casos. Describimos una serie de casos vista en dos hospitales de referencia de nuestro país. Material y métodos: Estudio observacional con muestreo intencional o de conveniencia de registros médicos de pacientes con $\mathrm{AR}$ encuadrados en una gama variada de compromiso parenquimatoso pulmonar. $\mathrm{La}$ selección de casos es con fines ilustrativos. Resultados (Descripción de los casos): Caso 1: Varón de 61 años, hipertenso, fumador, AR desde 40 años que refiere disnea de larga data. Consulta por cuadro infeccioso respiratorio y en las imágenes (TAC) llama la atención patrón de UIP. FR (+++); Caso 2: Mujer de 44 años, que refiere dolores articulares de tres años de evolución con cuadros bronquiales a repetición. Disnea de hace tres meses. TAC: patrón NSIP. Ecocardiografia: Hipertensión pulmonar (PSAP: $71 \mathrm{mmHg}$ ). FR (+++); Caso 3: Mujer de 52 años portadora de AR de larga data y síndrome bronquial obstructivo desde hace dos años. FR (+). TAC: Bronquiectasias lingulares y tree in bud localizado contralateral; Caso 4: Varón de 63 años, fumador, portador de AR larga data. Consulta por pérdida de peso y hallazgos radiológicos. Sin síntomas respiratorios. TAC: Nódulos periféricos bilaterales, algunos cavitados. Investigación para neoplasia: Negativa. Discusión: Los casos aquí presentados (UIP, NSIP, bronquiectasias y nódulos reumatoides) forman parte del variado repertorio del compromiso parenquimatoso pulmonar en la AR. Debemos recordar otras manifestaciones como la neumonitis intersticial linfocítica, el daño alveolar difuso, la neumonía organizante criptogenética, afección por drogas y las infecciones, entre otras.

\section{4}

\section{Efectos del ejercicio domiciliar durante 4 semanas en pacientes con EPOC}

\section{Agüero A, Fernández J, Chaparro G, Silvero G, Pérez D}

Dpto. Docencia INERAM

Introducción: Ante la escasa disponibilidad de centros de rehabilitación pulmonar en el Paraguay, los neumólogos sugieren ejercicios domiciliarios como complemento terapéutico en los pacientes con EPOC; muchas veces sin la garantía de adherencia, sin protocolos estandarizados y sin indicadores que puedan mostrar algún impacto. Con el objetivo de evaluar un breve programa de entrenamiento domiciliar, diseñamos el siguiente estudio. Material y métodos: Estudio experimental abierto en pacientes con dx de EPOC del consultorio externo del INERAM seleccionados al azar (octubre-diciembre 2012). Criterios de inclusión: dx confirmado por espirometría, enfermedad estable (>3 m), exclusión de otras enfermedades limitantes. Consentimiento informado. Procedimientos: Espirometría basal y aplicación de los siguientes indicadores: a) cuestionario IPAQ (International Physical Activity Questionnaire); b) escala de disnea x MRC (Medical Research Council); c) TM6M; d) índice BODE (IMC, grado de obstrucción, grado de disnea, capacidad de ejercicio), y e) Cuestionario HAD (Hospital Anxiety and Depression Scale). Intervención: programa de entre- 
namiento de cuatro semanas que consistió en sesiones domiciliarias de 30 minutos de caminata tres veces por semana, y la utilización de espirometría incentivo (Trifló ${ }^{\circledR}$ ) diariamente. Durante el entrenamiento se proveyó de supervisión a los pacientes con al menos una visita semanal y llamadas telefónicas para su incentivo. A los 30 días se midieron nuevamente los indicadores para su comparación. Software estadístico: Graphpad instat ${ }^{\circledR}$. Resultados: Se incluyeron a 20 pacientes (una mujer), $64 \pm 9$ años (ds), IMC $24 \pm 5$ (ds), $\mathrm{VEF}_{1}$ posBD $=54 \pm 11 \mathrm{~L} / \mathrm{s}(13 \mathrm{GOLD}$ II y 7 GOLD III), IPAQ: $40 \% \geq 2$. Medidas basales: MRC: 25\%:2, TM6M:362 \pm 66 m (72 $\pm 13 \%)$, BODE: $2 \pm 1$, HAD: $20 \%$ ansiedad. Las medidas realizadas postintervención (MRC: 15\%2, TM6M $375 \pm 71$ m, BODE: $2 \pm 1$, HAD: $15 \%$ ansiedad) no demostraron diferencias significativas $(\mathrm{p}>$ $0.05)$. Se constató diferencia clínicamente significativa en el TM6M en 3 pacientes (> $54 \mathrm{~m})$. Al ajustar los análisis según GOLD e IPAQ, tampoco hubo significantes diferencias. Discusión: No existen diferencias entre evaluaciones pre y pos intervención aquí efectuada. Al no medir calidad de vida, los parámetros objetivos en la muestra analizada no parecen mejorar después de cuatro semanas de ejercicios. Llama la atención perfomance física $(40 \%>2)$ de los pacientes estudiados aquí. Interpretación: ¿EPOC no severos en la muestra?, ¿tiempo insuficiente de entrenamiento?

\section{5}

\section{Criptococosis pulmonar en pacientes no HIV}

\section{Aguilera O, Fusillo J, Aguilar G, Araujo $P$, Pérez D}

Dpto. Docencia INERAM

Introducción: La criptococosis pulmonar es más común en el huésped inmunocomprometido; aunque puede ocurrir en individuos con inmunidad preservada, en los que suele ser un hallazgo incidental, presentándose como nódulos subpleurales solitarios o múltiples con o sin cavitación. Relatamos el caso de una paciente con características clínicas ilustrativas, visto en servicio de referencia. Descripción del caso: Mujer de 21 años, sin comorbilidades aparentes, consulta por dolor dorsolumbar derecho más fiebre de días de evolución. Analítica: Leucocitos: 6,500/ $\mathrm{mm}^{3}$ (Neutrófilos: $80 \%$ ). Test rápido HIV (-). TAC tórax: área de consolidación con broncograma aéreo en base hemitórax derecho. Falla de respuesta a esquema ceftriaxona + levofloxacina. PCR TB (-); ANA y Anti-DNA (-). Ecografía: líquido pleural laminar en sitio afectado. Se decide seguimiento ambulatorial. Reingresa por empeoramiento del dolor y disnea. Punción de opacidad, guiada bajo pantalla: examen en fresco de material informa levaduras compatibles con Cryptococcus neoformans. Serodetección de antígeno criptococócico por látex: positivo. Anatomía patológica: granulomas epitelioides donde se identifican escasas estructuras birrefringentes tipo micóticas. ELISA HIV (-). Inicia tratamiento con fluconazol $400 \mathrm{mg}$. La TAC de control cuatro meses después denota mejoría importante. Discusión: Es raro encontrar criptococosis pulmonar en forma de consolidación como vemos en este caso, aunque la localización (segmentos inferiores) es el sitio más afectado. El dolor pudo deberse a la localización periférica de la infección, ya que en algunos casos puede ser asintomático. Las guías IDSA recomiendan tratamiento por un 6-12 meses y en caso de falla en la respuesta, evaluar cirugía.

\section{6}

\section{Síndrome de distress} respiratorio agudo: Serie de casos

\section{Aluan A, Rodríguez S, Silvero G, Meilicke $C$, Pérez D}

Dpto. Docencia INERAM

Introducción: La dificultad respiratoria que no sea de origen cardíaco, con una semana de evolución, más opacidades bilaterales en la radiografía torácica y la hipoxemia $\left(\mathrm{PaO}_{2} / \mathrm{FiO}_{2} \leq 300 \mathrm{mmHg}\right)$ definen los cuatro criterios diagnósticos del síndrome de distress respiratorio agudo (SDRA), causa frecuente de ingreso a UCIA. Presentamos las carac- terísticas clínicas de una serie de casos de un hospital de referencia. Material y métodos: Estudio observacional (serie de casos) de registros médicos de casos de SDRA vistos en nuestra UCIA, en un período comprendido entre 2011-2014. Se consignan la frecuencia de variables demográficas, clínicas y terapéuticas. Resultados: Se incluyeron 16 pacientes (50\% sexo masculino), con una edad promedio de $49 \pm 15$ años (ds). Severidad de SDRA: Leve (31.3\%); Moderado (50\%) y Severo (18.7\%). En asistencia respiratoria mecánica el $87.5 \%$ utilizó la modalidad de presión controlada (PCV), PEEP promedio: $10 \mathrm{cmH}_{2} \mathrm{O}$ (rango 5-20). El promedio de días de ventilación mecánica fue de $11.6 \pm 13.2$ días. Uso de corticoides en 14 casos. La mortalidad intrahospitalaria fue de $43.7 \%$. Discusión: El SDRA es una causa mayor de muerte en las UCIAs y pese a la ventilación protectora y a los curares, los días de ventilación mecánica consignados en esta serie son similares a los reportados en varias regiones. La tasa de mortalidad sigue siendo alta, del orden del $40 \%$, similar a la relatada en esta observación.

\section{7 \\ Hemoptisis de causa inusual en adulto joven}

\section{Arce D, Fretes J, Guggiari R, Silvero G, Chaparro G, Pérez D}

Dpto. Docencia INERAM

Introducción: En adultos jóvenes (1835 años) la hemoptisis se produce por causas infecciosas (33\%) y sólo en $17 \%$ por enfermedades neoplásicas, según las escasas series halladas en la literatura. Presentamos un interesante caso clínico paciente visto en hospital de referencia. Descripción del caso: Varón de 24 años, sin comorbilidades aparentes, con el antecedente de tuberculosis tratada 12 años atrás que consulta por fiebre de un mes de evolución, más dolor torácico en base hemitórax derecho junto a tos productiva y hemoptisis de aproximadamente $50 \mathrm{~cm}^{3}$. En cinco oportunidades. Internado para estudios, presenta signos vitales estables y disminución de murmullo vesicular base 
derecha. Analítica sin particularidades. TAC tórax: atelectasia lóbulo inferior izquierdo. Broncoscopia: segmento posterior de lóbulo inferior desemboca en cavidad. Se sugiere cirugía. Debido al gran compromiso del lóbulo inferior del pulmón izquierdo, se realiza lobectomía inferior izquierda mediante toracotomía. Informe patología: quiste tipo bronquial con proceso inflamatorio crónico parietal. El paciente evolucionó favorablemente, la hemoptisis cesó y, posteriormente, el mismo fue dado de alta del servicio. El seguimiento del paciente no pudo concretarse debido a que el mismo no acudió a la cita fijada para control. Discusión: La hemoptisis es una forma rara de presentación de los quistes broncogénicos $(9 \%$ de algunas series), siendo los síntomas más comunes: tos, dolor y disnea. Los quistes broncogénicos constituyen un amplio espectro de malformaciones congénitas traqueobronquiales que se originan de la porción ventral del intestino primitivo. La mayoría se sitúa en el mediastino; aunque pueden ser de localización parenquimatosa en el tercio de los casos. El abordaje quirúrgico es el tratamiento definitivo. En SciELO y PubMed existen menos de 1,000 artículos referentes a esta enfermedad.

\section{8}

\section{Análisis comparativo del CAT y del MRC en pacientes con EPOC}

\section{Arruabarrena R, Bogarin $P$, Maldonado L, Sosa L, Molinas G, Pérez $D$}

Dpto. Docencia INERAM

Introducción: Hemos realizado este estudio con el objetivo de evaluar la aplicabilidad de los cuestionarios CAT (COPD Assessment Test) y el mMRC (modified Medical Research Council) en el escenario de la salud pública de nuestro país. Material y métodos: Estudio observacional de pacientes con dx de EPOC del consultorio del INERAM. Se incluyeron pacientes estables en quienes se confirmó el dx por espirometría (GOLD, 2011). El cuestionario CAT debe ser autoaplicado y considerando la población bilingüe, se tradujo el CAT a una versión en guaraníjopará. En una primera fase se evaluó a los pacientes mediante CAT, CATjopará y MRC. Con el objetivo de evaluar la reproducibilidad, se volvieron a efectuar los cuestionarios 45 días después. Todas las evaluaciones fueron hechas por un mismo médico. Análisis Graphpad instat $^{\circledR}$. Resultados: Se incluyeron a 30 varones (edad: $67 \pm 9$ años: ds), $23 \%$ concluyeron estudios primarios, GOLD 2: $23 \%$ y GOLD 3-4 77\%, que fueron evaluados al inicio y al final de un período de 45 días. Sólo un paciente pudo hacer cuestionarios autoaplicados, casi todos necesitaron de ayuda del profesional. Evaluación inicial: CAT $11.8 \pm 5.5$, CATjopará $11.6 \pm 5.5$ y mMRC $2.1 \pm 5$. Fue notoria la mayor comprensión al aplicar el CATjopará. Segunda evaluación: CAT $10.3 \pm 5.3$, CATjopará $9.7 \pm 5.3$ y mMRC $2.1 \pm 1.06$. Observaciones: a) se mantiene proporcionalidad entre mMRC y CAT (coef. correlación: 0.98 -alto-,esto es: los más disneicos tienen alto mMRC y CAT); por ende, la clasificación fenotípica del GOLD no mostró diferencias (excepto en un caso), al emplear uno u otro cuestionario (con CAT: $\mathrm{A}=6, \mathrm{~B}=22$ y $\mathrm{C}=$ 2, con mMRC $A=5, B=23, C=2)$; b) no se constataron diferencias entre CAT y CATjopará ( $p>0.05)$; c) no hubo diferencia intraindividual significativa entre los cuestionarios aplicados a lo largo del intervalo aquí estudiado ( $p>0.05$ ). Conclusiones: Los hallazgos en esta muestra denotan reproducibilidad y correlación entre CAT y CATjopará, además de guardar proporcionalidad con mMRC. Esto homogeneizó la clasificación fenotípica GOLD utilizando ya sea CAT o mMRC. Esto es discutido por varios estudios y es probablemente por el tamaño de muestra aquí estudiada, así como también por el eventual sesgo que implica la injerencia de los evaluadores en la elaboración del cuestionario. Es de mucho interés mencionar el perfil sociocultural de los pacientes de nuestro análisis.

9

\section{Manejo terapéutico de la proteinosis alveolar pulmonar}

Ayala J, Sotelo F, García A, et al.

Hospital Alta Complejidad "JD Peron" (Fomosa-Argentina)

Introducción: La proteinosis alveolar pulmonar ((PAP) fue descrita por primera vez en 1958. Es una entidad rara de curso variable debido a un trastorno en el que se acumula un material lipoproteináceo PAS (+) dentro de los alvéolos pulmonares produciendo insuficiencia respiratoria. Prevalencia: 0.37 por cada 100,000 personas. Se encuentra dentro de las enfermedades pulmonares intersticiales raras. Propósito: Demostrar que un tratamiento multidisciplinario puede contribuir a mejorar la calidad de vida en pacientes que padecen PAP. Caso clínico: Mujer de 47 años, reside en Paraguay, sin antecedentes de enfermedades laborales o sistémicas. Consulta en mayo de 2010 por disnea CF I-II y tos no productiva de un año de evolución. 1) Rx tórax: patrón en vidrio deslustrado, bilateral y simétrico de distribución perihiliar y bibasal. 2) $T C$ tórax: con aspecto de «empedrado loco» (crazy paving), también observado en una amplia variedad de enfermedades pulmonares 3) Espirometría (mayo/2010): FVC 1.57 (45\%); FEV1:1.33 (45\%); FEV1/FVC: 84.7; PEF: 6.36 (90\%); 6 MWT' (21\%): $\mathrm{SO}_{2}$ (96/84\%); BORG (I/III), recorrió 522 m (100\% teórico). 4) Colagenograma: negativo. 5) VIH: No reactivo. Se realizó diagnóstico de PAP por aspecto macroscópico lechoso del BAL, con material amorfo granular PAS (+) y biopsia transbronquial (BTB). Anatomía patológica: compatibles con PA. En el año 2010 se realizaron lavados pulmonares segmentarios en 3 oportunidades (mayo, septiembre y noviembre), a pesar de los cuales presentó progresión de su enfermedad y de su disnea a CF IV, con requerimiento de oxigenoterapia continua. Espirometría (enero/11): no logra realizar maniobras reproducibles, $M V V$ : $306 M W T^{\prime}$ : (con cánula nasal a 2.5 litros/min.): $\mathrm{SO}_{2}(92 / 88)$ BORG: (I/III), $58 \mathrm{~m}$ (428 m) abandona la marcha. BMI: 18.7. SGRQ: 54.1. Se realiza lavado pulmonar total (LPT) en 3 oportunidades (enero, febrero y abril 2011) se envían muestras: a) Determinación de auto-anticuerpos anti-GM-CSF en suero: $(0.8855 \pm 0.0175) \mathrm{nm}$ muestra: + , 
$* * * \mathrm{p}<0.001$. b) Determinación de ácido hialurónico en el BAL: niveles elevados. Los LPT fueron realizados con volúmenes crecientes de material instilado, en la primer vez: 6 litros, en la segunda 8 litros y en la tercera 12 litros. Concomitantemente se inicio G-CSF (FILGRASTIM), previo consentimiento informado, rehabilitación pulmonar, soporte psicoterapéutico y nutricional, permitiéndonos corregir todos los parámetros clínicos y aportar mejoría en su calidad de vida. Obtuvimos espirometría (mayo/11): FVC: 1.15 (39\%), FEV1: 1.08 (42\%), FEV1/FVC: 93, PEF 60, $M V V$ : 63. 6MWT: (con cánula nasal a 1.5 litros/ min) $\mathrm{SO}_{2}(96 / 95 \%)$; BORG (I/II), recorrió 352 m (teórico: 428 m). SGRQ. 22. BMI: 22. Conclusión: Hemos evidenciado que un tratamiento adyuvante multidisciplinario posibilita mejorar la calidad de vida de estos pacientes. Queda como desafío un estudio con mayor número de pacientes que reciban tratamiento farmacológico (Filgrastim).

\section{0}

Experiencia terapéutica de la estenosis traqueal benigna (ETB) con aplicación de mitomicina $\mathrm{C}$ (MMC) como coadyuvante de la broncoscopia rígida

Ayala J, Sotelo F, García A,
et al.

Hospital Alta Complejidad “JD Perón” (Fomosa-Argentina)

Introducción: La ETB no es una complicación infrecuente asociada a la intubación prolongada. Es difícil de tratar y el enfoque quirúrgico se asocia con un riesgo significativo de complicaciones. La estenosis recurrente por tejido de granulación requiere procedimientos invasivos repetidos. La aplicación tópica de MMC tópica endotraqueal reduce la formación de tejido de granulación y evita la reestenosis. La MMC es un antibiótico que se aisló a partir de la bacteria Streptomyces en caespitosus 1956, pero no es útil como agente antimicrobiano debido a su toxicidad. Su forma de $\mathrm{C}$ es un agente alquilante bi o trifuncional que inhibe la síntesis de ácido desoxirribonucleico (ADN) y en menor medida también inhibe la síntesis de ARN y proteínas (inhibidor potente de fibroblastos). Se utilizó por primera vez como un medicamento contra el cáncer. También ha sido utilizado en procedimientos oftalmológicos para reducir cicatrización de la córnea y recién en el tratamiento ETB. Material y métodos: Presentamos dos pacientes con ETB donde aplicamos MMC como tratamiento adyuvante antifibrosante posterior a la dilatación con broncoscopio rígido y resección con radiofrecuencia. Caso 1: Mujer, 37 años, con ETB postintubación prolongada, colocación de stent en mayo 2009, extraído en julio 2010 por halitosis. Se le realizaron en tres oportunidades broncoscopias rígidas con cortes con radiofrecuencia y dilatación mecánica en el año 2011 (agosto, septiembre y diciembre). Caso 2: Mujer, 16 años, con ETB postintubación prolongada, se le realizaron en dos tiempos broncoscopia rígida y disección con radiofrecuencia y dilatación mecánica (octubre y diciembre 2011). En ambos casos se observó reestenosis a través de controles periódicos con espirómetro (caída progresiva del PEF) con asociación de disnea y estridor, decidiéndose la utilización de coadyuvancia con MCC al tratamiento convencional para ambos: Caso 1 (enero 2012), Caso 2 (febrero de 2012). La concentración de MMC para uso tópico fue a razón de 5 mg/mL. En marzo de 2012 ambas pacientes fueron topicadas nuevamente con motomicina C. Resultados: Creemos que esta terapéutica coadyuvante de la broncoscopia rígida nos ha dado resultados positivos en nuestra experiencia ya que hemos observado estabilidad de la ETB en ambos casos, medidos por mejoría de parámetros clínicos (disnea) y espirometría. Discusión: Nos queda como desafío contar un mayor número de pacientes que hayan recibido este tratamiento como experiencia y el seguimiento en el tiempo de la necesidad de nueva topicación. En nuestra experiencia hemos tenido con los casos expuestos un retraso en el tiempo de reestenosis traqueal.

\section{1 Quiste hidatídico en lóbulo superior derecho}

Britez H, Calderoli F, Hasin G, Arce C, Soskin A

Cátedra Neumología-Hospital ClínicasFCMUNA

Introducción: La hidatidosis es una zoonosis causada por el estadio larvario del cesto de Echinococcus granulosus, responsable de importante morbimortalidad en el mundo. Las regiones con mayor prevalencia a nivel mundial son: EuroAsia, África (región nordeste), Australia y América del Sur. En América del Sur, la enfermedad existe en la mayoría de los países, pero Argentina, Bolivia, Brasil, Perú y Uruguay, son aquellos donde la hidatidosis constituye un importante problema de salud pública. Caso clínico: E.G. masculino, 21 años, procedencia: San Juan Nepomuceno-Paraguay. No ha viajado al extranjero; ocho días antes del ingreso manifiesta dolor en cara anterior de tórax lado derecho, inicio agudo, moderada intensidad, irradia a epigastrio, tipo opresivo; la radiografía de tórax informa: mediastino ensanchado a derecha, a expensas de opacidad redondeada, homogénea, de bordes definidos, que parece formar parte del mediastino anterior; tomografía de tórax: tumoración en mediastino anterior de contenido líquido. Serología para hidatidosis: negativo. Se procedió a extracción de la tumoración. La anatomía patológica informa: quiste hidatídico de $9 \mathrm{~cm}$ del lóbulo superior pulmón derecho con presencia de múltiples escólex. Discusión: Iniciamos con albendazol 400 mg/día posterior a cirugía. Las opciones de tratamiento: farmacológico, cirugía, esperar y observar. El albendazol es de elección; diariamente a una dosis de 10-15 $\mathrm{mg} / \mathrm{kg} /$ día; también es utilizado antes de las cirugías programadas de quistes hidatídicos a razón de 10-15 mg/kg/día durante los 30 días previos a la cirugía y los 60 días posteriores a la misma. El tratamiento quirúrgico está indicado en todo quiste hidatídico pulmonar y tiene como objetivo erradicar el parásito, evitar la recidiva y presentar la menor morbimortalidad.

12

Linfangioleiomiomatosis: A propósito de dos casos 
Bustios R, Cano E, Sosa L, Rodríguez C, Caballero E, Pérez D

Dpto. Docencia INERAM

Introducción: La linfangioleiomiomatosis pulmonar (LAM) es una enfermedad intersticial idiopática de muy baja ocurrencia caracterizada por una proliferación anormal de músculo liso en pulmón, de aspecto benigno y de predominio peribroncovascular, que provoca obstrucción de linfáticos, vasos sanguíneos y bronquiolos. Es raramente presentada en congresos de nuestro país. Presentamos dos casos vistos en el servicio. Descripción de los casos: Caso 1: Mujer de 47 años, fumadora, con historia de 3 días de evolución de disnea en reposo de inicio súbito. Antecedentes remotos: 10 años atrás neumotórax derecho espontáneo. Laboratorio: Hg 9.9 g\%, ELISA-HIV negativo, $\alpha 1$ AT: $255 \mathrm{mg} / \mathrm{dL}$ (23-388 mg/dL). Ecografía abdominal: mioma uterino y litiasis vesicular. Rx de tórax: hipertransparencia unilateral (izquierda). TAC tórax de cortes finos: quistes difusos múltiples y neumotórax bilateral asimétrico a predominio izquierdo. Anatomía patológica de biopsia pulmonar a cielo abierto: Dilataciones quísticas múltiples en parénquima pulmonar, algunas subpleurales y otras intraparenquimatosas. Acúmulo de tejido muscular liso en su pared. Caso 2: Mujer de 40 años, no fumadora pero con múltiples comorbilidades. Disnea de tres meses de evolución progresiva más tos productiva y hemoptisis en varias oportunidades más dolor torácico intenso. Signos vitales y análisis sin datos llamativos. Examen físico: Hemangioma frontal. TAC torácica denota múltiples imágenes quísticas. Espirometría normal. Biopsia por toracotomía: linfangioleiomiomatosis. Discusión: El diagnóstico de LAM puede ser clínico ante las típicas imágenes tomográficas y si está presente al menos una de las siguientes: angiomiolipomas, quilotórax, linfangioleiomiomas, células LAM en ganglios o esclerosis tuberosa. Caso contrario, se podría realizar la cirugía diagnóstica, generalmente por toracoscopia. Debido a su baja prevalencia, la LAM es una enfermedad poco conocida que afecta predominantemente a las mujeres. El trasplante de pulmón constituye la mejor opción terapéutica en fases avanzadas. Las opciones médicas actuales en estudio son: sirolimus, doxiciclina e inhibidores de aromatasa.

13

\section{Tumor fibroso pleural solitario: Reporte de caso}

Cattoni M, Fusillo J, Palacios Z, Elizaur S, Aquino M, Pérez D

Dpto. Docencia INERAM

Introducción: Los tumores fibrosos solitarios son neoplasias raras que surgen de células mesenquimales indiferenciadas en el revestimiento submesotelial de la cavidad pleural. 10 a $20 \%$ son clasificados como malignos, que se caracterizan histológicamente por mitosis, necrosis, atipia e hipercelularidad. En PubMed existen menos de 400 artículos sobre esta entidad hasta la fecha. Presentamos un caso visto en el servicio. Relato del caso: Mujer de 72 años, hipertensa, acude por disnea de 9 meses de evolución, tos seca y dolor torácico, más decaimiento y pérdida de peso. Disminución de murmullo vesicular y matidez en base y campo pulmonar medio izquierdo, más edema bilateral de miembros inferiores. Rx tórax: velamiento costofrénico izquierdo. TAC tórax: masa campo medio e inferior izquierdo. Resección total de la masa mediante toracotomía. La biopsia y la inmunohistoquímica concluyeron que el voluminoso tumor se trataba de un tumor fibroso pleural. Posteriormente, durante su evolución clínica presentó notable mejoría de la sintomatología. En controles radiológicos, meses después de la intervención no se constata recidiva. Discusión: Los tumores primarios de la pleura presentan patrones difusos o de neoplasias localizadas. El tumor fibroso pleural solitario constituye el $5 \%$ de todos los tumores pleurales. Ocurre predominantemente entre la 6 ta o $7 \mathrm{ma}$ décadas con igual distribución entre géneros. Los síntomas se presentan en $75 \%$ de casos malignos, y de modo variable (54-67\%) en los benignos. El tamaño en este último caso determina los síntomas. El tamaño promedio es variable, aunque no suele alcanzar las dimensiones del caso aquí presentado. La histoquímica puede diferenciar otros diagnósticos (sarcoma sinovial, fibromatosis, tumor de vaina neuronal, etc.), como lo hizo en el cuadro relatado.

\section{4}

\section{Exploración quirúrgica del mediastino}

\section{Chaparro A, Gutiérrez I, Benítez W, Guggiari $R$}

\section{Dpto. Docencia INERAM}

Introducción: Para establecer el diagnóstico histológico y el tratamiento a emplear en las patologías mediastinales, se necesita frecuentemente del acceso quirúrgico. Presentamos el siguiente estudio con el objetivo de describir los procedimientos quirúrgicos prevalentes en un centro de referencia. Métodos: Se presentan 19 pacientes con lesiones mediastinales, con edad entre 19 y 75 años, tratados entre noviembre de 2011 y septiembre de 2014 y a quienes se les realizó una exploración mediastinal para obtener muestra tisular para biopsia y con fines terapéuticos en algunos casos. La intervención se consideró útil cuando la muestra fue suficiente para el estudio histológico o, en su defecto, impactó positivamente en el desenlace de la enfermedad. Resultados: Se realizaron 19 exploraciones del mediastino con fines diagnósticos y de tratamiento, siendo 5 mediastinoscopias cervical y 14 mediastinotomías anteriores (Cx de Chamberlain), en 6 mujeres y 13 hombres, de los cuales se encontraron 1 caso de miastenia gravis, 9 casos de tumores malignos, 4 casos de linfoma de Hodgkin, 2 casos de mediastinitis necrotizante descendente, 3 casos de tumores benignos. En 17 pacientes (89.5\%) se obtuvo el diagnóstico en la primera exploración y en 2 (10.5\%) hubo que practicar una segunda exploración que consistió en una lobectomía superior, posterior a una mediastinoscopia exploradora en el primer caso, y toracotomía exploradora con extirpación del tumor mediastinal posterior a mediastinotomía anterior en el segundo caso, para alcanzar el diagnóstico y tratamiento definitivo. Sin complicaciones posoperatorias. No 
hubo caso de muerte relacionada con el proceder. Conclusiones: La exploración mediastinal (mediastinoscopia cervical y mediastinotomía anterior) resulta efectiva cuando se necesita establecer, con morbilidad mínima y sin mortalidad, el diagnóstico histológico de lesiones expansivas mediastinales, y con fines terapéuticos en ciertos casos.

\section{5}

\section{Sarcoidosis cutánea, uveítis y lesiones quísticas pulmonares}

\section{Chaparro A, Maldonado L, Gorostiaga G, Pérez D}

Dpto. Docencia INERAM

Introducción: La sarcoidosis es una enfermedad inflamatoria crónica multisistémica de etiología desconocida caracterizada por la presencia de granulomas epiteliodes en los órganos afectados. La afección cutánea y la ocular son infrecuentes y las lesiones quísticas en pulmón son prevalentes en el estadio IV. Excepcionalmente se describen formas quísticas en estadios menos avanzados. Presentamos un interesante caso visto en nuestro servicio. Relato de caso: Mujer de 51 años, extabaquista, portadora de hipertensión arterial e hipotiroidismo que consulta a hospital de referencia por dificultad respiratoria a grandes esfuerzos y dolor torácico, con síndrome de ojo rojo bilateral y lesiones nodulares en miembros superiores e inferiores (presenta lesiones en piel y ojo de dos años de evolución desde 2012). Analítica: Hgb:11,4 mg/dL; Hto 36\%, VSG:103 mm; PPD:12 mm; Serología HIV: (-); Dosaje de enzima conversora de angiotensina: $67 \mathrm{mg} / \mathrm{dL}$ (vn: 8-52 mg/dL). Rx tórax: patrón hiliar bilateral. TAC tórax: adenomegalias mediastinales y quistes de varios tamaños bilaterales, algunos subpleurales. Algunos quistes tienen refuerzos nodulares en su pared. Ecografía renal: normal. Biopsia transbronquial: antracosis. Biopsia de piel: proceso inflamatorio crónico granulomatoso de tipo sarcoide. Se inicia tratamiento con corticoides que se suspende por escasa tolerancia. Después de una mejoría inicial, las lesiones cutáneas empeoran, así como los quistes pulmonares posterior a abandono de tratamiento. Discusión: Dentro del enfoque de unidad diagnóstica, creemos que este caso ilustra un cuadro de sarcoidosis quística. La sarcoidosis bullosa es descrita en el contexto de estadios IV y probablemente sea secundaria a la distorsión de la arquitectura. La sarcoidosis quística podría deberse a un mecanismo de válvula de la sarcoidosis endobronquial. Existe escasa literatura sobre esta forma de presentación.

\section{6}

\section{Espirometría en pueblos originarios del Paraguay: Maká, Nivacle y Mbya}

\section{Chaparro L, Pérez D}

Dpto. Docencia INERAM

Introducción: Estudios experimentales en años anteriores demostraron que en una muestra poblacional de nativos Maká, las ecuaciones de referencia utilizadas rutinariamente distan significativamente de un ajuste conveniente. Con el objetivo de evaluar si este fenómeno es similar para otras etnias, desarrollamos el siguiente análisis. Material y métodos: Estudio observacional en el que se efectuó espirometría forzada en una muestra de individuos de pueblos originarios (Maká, Nivaclé y Mbyá), sin aparente comorbilidad pulmonar. Se compararon los valores observados de $\mathrm{VEF}_{1}$ y CVF a los valores esperados, resultantes de la ecuación de NHANES y del GLI (Global Lungs Initiative). Se considera que una ecuación ajusta a sus valores cuando la diferencia entre observado y esperado es $<100 \mathrm{~mL}$. Test t pareado para análisis estadístico. Graphpad Instat ${ }^{\circledR}$ para análisis estadístico. Resultados: Se incluyeron en el ensayo 60 individuos (20 de cada etnia). Datos antropométricos: Edad: $45 \pm 10 \mathrm{a}, 46 \pm$ 11a, $40 \pm$ 13a (Maká, Nivaclé y Mbyá, respectivamente) menor altura y peso de los Mbyá ( $\mathrm{p}<0.05)$. No existió diferencia interétnica significativa $(\mathrm{p}>0.05)$ entre los valores espirométricos observados (media $\pm d s$ ): CVF:4.5 $\pm 0.84 \mathrm{~L}_{,} \mathrm{VEF}_{1}: 3.58$ $\pm 0.64 \mathrm{~L} / \mathrm{s}$ en los Maká, CVF:4.11 $\pm 1.54 \mathrm{~L}$, $\mathrm{VEF}_{1}: 3.01 \pm 1.28 \mathrm{~L} / \mathrm{s}$ en los Nivaclé y CVF:4.45 $\pm 1.17 \mathrm{~L}, \mathrm{VEF}_{1}: 3.54+1.03 \mathrm{~L} / \mathrm{s}$ en los Mbyá. Aunque sólo existió diferencia estadística para los valores observados y esperados de CVF de los Mbyá y VEF1 de los Nivaclé, las ecuaciones del NHANES son bastante erráticas en su predicción (expresado como delta Esp-Obs): tanto para la CVF (235 mL Maká, $728 \mathrm{~mL}$ Nivaclé y -714 mL Mbyá) como para el $\mathrm{VEF}_{1}$ (204 mL Maká, 875 Nivaclé y -110 Mbyá). El GLI tampoco mejora mucho, así CVF (-290 mL Maká, 740 mL Nivaclé y 1,110 mL Mbyá) como para el $\mathrm{VEF}_{1}$ (1170 mL Maká, -1130 Nivaclé y -110 Mbyá). Discusión: La raza es determinante en la función pulmonar. La literatura menciona que afroamericanos y asiáticos poseen valores de volúmenes normales más bajos que los caucásicos. Otros estudios, sin embargo, mencionan que algunos pueblos originarios de Estados Unidos y los mexicano-americanos tienen valores aproximados a los caucásicos. En este primer estudio sobre función pulmonar en originarios del Paraguay, hemos encontrado dispersión llamativa entre las actuales ecuaciones de predicción.

\section{7}

\section{Asociación tuberculosis pulmonar- paracoccidioidomicosis}

\section{Chaves D, Calderoli F, Hasin G Rodríguez $C$}

Cátedra Neumología-Hospital Clínicas-FCMUNA

Introducción: La paracoccidioidomicosis produce lesiones en pulmones, piel, mucosas y ganglios, como también puede generalizarse con un cuadro clínico similar a la tuberculosis pulmonar. Su asociación con la tuberculosis se describe con una frecuencia aproximada del $15 \%$, con compromiso pulmonar de ambos en el servicio de referencia. Caso clínico: E.T. sexo masculino de 66 años procedente de un área rural de Horqueta. Seis meses de tos productiva, disnea de moderados esfuerzos, sudoración nocturna y pérdida 
de peso, se realiza RX de tórax: infiltrados reticulonodulillar bilateral. TACAR de tórax: Imágenes reticulonodulillares con presencia de fibrosis extensas bilaterales de vértice a base, además de bullas subpleurales bilaterales. Cultivo de esputo: Mycobacterium tuberculosis. Frotis de esputo: formas compatibles con paracoccidioidomicosis BAAR (-), serología para paracoccidioidomicosis:(+) inmunodifusión en gel de agar. Al examen físico no se observan lesiones mucocutáneas ni adenopatías. Se inicia tratamiento con antibacilares (2HRZE/4HR) e itraconazol $400 \mathrm{mg}$ por 6 días luego a $200 \mathrm{mg} / \mathrm{día}$ hasta completar seis meses con mejoría clínica. Comentario: Ante la presencia de paracoccidioidomicosis con afectación pulmonar, se buscó tuberculosis por la frecuente asociación. Ante la baciloscopia seriada de tres para BAAR (-) se insistió en la búsqueda de tuberculosis, retornando luego el cultivo por BACTEC 460 (+) para Mycobacterium tuberculosis (en siete días).

\section{8}

\section{Neumonitis intersticial usual como manifestación inicial de artritis reumatoide: Reporte de dos casos}

\section{Coronel R, Otazu F, Cartes G, Hellwig G, Pérez D}

\section{Dpto. Docencia INERAM}

Introducción: Algunos artículos plantean que las neumonitis intersticiales idiopáticas (NNI) podrían tratarse de formas frustradas de enfermedades del colágeno. La presentación inicial de éstas mediante NNI no es frecuente. Presentamos dos casos vistos en nuestro medio. Descripción de casos: Caso 1: Mujer de 62 años, quehaceres domésticos, consulta por disnea de un año de evolución sin otros síntomas. TAC tórax: panalización periférica extensa. Espirometría: CVF:1.61 L(66\%), $\mathrm{VEF}_{1} 1.33$ L(75\%) VEF${ }_{1} / \mathrm{CVF}:$ 82. Tras dos años de seguimiento refiere síntomas compatibles con artritis reumatoidea. FR $(+++)$; Caso 2: Mujer de 69 años, que- haceres domésticos consulta por disnea de dos años de evolución con empeoramiento progresivo desde hace seis meses, acompañada de tos seca. No bajó de peso. Screening cardiológico negativo. Recién tres meses antes de consulta presenta rigidez matutina de pequeñas articulaciones de mano, con dolor migratorio. Factor reumatoideo y anticuerpos anticitrulina $(++)$. TAC tórax: panalización periférica y distorsión de arquitectura de parénquima. CVF;1.42 L(52\%), VEF $1.23(58 \%)$, $\mathrm{VEF}_{1} / \mathrm{CVF}$ : 88. Discusión: El patrón de neumonitis intersticial usual (UIP) es la forma más común de las NNI secundarias a artritis reumatoide, y la supervivencia es mayor que en las formas idiopáticas. Se relata que, en hasta $10 \%$ de los casos, la UIP puede preceder a las manifestaciones floridas de la AR. Las hipótesis sobre las NNI como formas frustras de conectivopatías indiferenciadas surgen de estos hallazgos. En una de las mayores series que analiza este tema, la aparición de la sintomatología articular característica llevó en promedio 3.9 años. Los casos presentados aquí probablemente son los primeros en la literatura médica nacional.

19

Diagnóstico de la tuberculosis pulmonar y extrapulmonar en Paraguay con ayuda de la nariz electrónica. (Protocolo paranose.)

\section{Coronel R, Rodríguez M, Romero \\ $N$, Pérez D, Bruins $M$, Gerritsen JW, Yntema JB, Gómez $R$, Magis $C$}

Dpto. Docencia INERAM- Radboud University (Netherland)

Introducción: Pese a reportes preliminares sobre la alta sensibilidad $(93 \%)$ y especificidad (83\%) de la nariz electrónica para la detección de la TB pulmonar, se desconoce su aplicabilidad en formas extrapulmonares y en diferentes regiones. Objetivos: 1. Determinar la exactitud diagnóstica en la detección de la TB pulmonar; 2. Determinar la exactitud diagnóstica en la detección de la TB extrapulmonar; 3. Explorar los factores que influyen en la precisión diagnóstica de formas pulmonares y extrapulmonares. Material: Diseño: Estudio observacional de muestreo consecutivo de pacientes con sospecha de TB reunidos en 4 grupos: 1) TB pulmonar (n20); 2) TB extrapulmonar ( $\mathrm{n}=20)$; 3) neumopatas:asma, EPOC, bronquiectasias $(n=20)$ y 4$)$ grupo control sano c/emparejamiento sociodemográfico ( $\mathrm{n}=50$ ); El Dx de TB se establecerá mediante clínica, esputo, cultivo y PCR en tiempo real, análisis químico del líquido pleural y Rx de tórax. Criterios de inclusión: $>18$ años, firma de consentimiento informado, capacidad para expectorar (grupos 1, 2 y 3 si existe tos), no haber recibido antibacilares, baciloscopia positiva (grupo 1), pleuresía exudativa mononuclear o BAAR o PCR (+) en líquido pleural, y exclusión de Dx de TB en grupo 3. Criterio de exclusión: dificultad para respirar en la nariz electrónica. Recolección de datos: Formulario clínico y colecta de muestra de aire exhalado en la nariz electrónica (AENOSE ${ }^{\circledR}$ ) durante 5 minutos. Instrumentos: El AENOSE ${ }^{\circledR}$ (eNOSE, BV, Zutphen, Holanda) o nariz electrónica es un dispositivo que mide la composición del aire mediante modulación térmica de la superficie de un sensor (http://www.enose. nl) Lugar de estudio: Hospital de referencia la recolección de muestras (clínica y aire exhalado) se realiza en un habitación designada. Estudios microbiológicos: laboratorio del centro de referencia y laboratorio central (MSP). Los datos se analizaran en la Universidad Radboud (Holanda). Métodos: Exceptuando el grupo 4, se reclutan los pacientes del consultorio externo del centro de referencia. Después de completar el formulario clínico y microbiológico, los pacientes exhalan durante 5 minutos en la nariz electrónica. Existen consideraciones éticas acordes con Helsinki (2008) y los análisis estadísticos se realizan en la Universidad de Radboud. El cronograma se extiende hasta diciembre 2014.

\section{0 \\ No todo lo que chilla es asma: Adenocarcinoma de tráquea}


Fleitas V, Estigarribia C, Aguayo D, Mura R, Pérez D

Dpto. Docencia INERAM

Introducción: Los síndromes bronquiales pueden ser causados por tumores. Los tumores malignos primarios de tráquea son raros; en el adulto representan el $90 \%$ de todos los tumores traqueales. El carcinoma adenoideo quístico es el segundo más frecuente con aproximadamente $10-15 \%$ de los casos. Los síntomas son inespecíficos y los más frecuentes suelen ser: tos, ronquera, disnea, sibilancias y estridor. La broncoscopia es el método para la obtención de tejido para el estudio histológico. La resección quirúrgica es el tratamiento de elección siempre que sea posible. Relatamos un caso visto en nuestro servicio. Reporte de caso: Varón de edad, 19 años, tratado por asma bronquial desde hace 4 años, presenta dificultad respiratoria progresiva. Se realizan estudios de imágenes y se visualiza masa intratraqueal. Es remitido al INERAM. Se hace biopsia mediante endoscopia y con diagnóstico de carcinoma adenoideo quístico en tercio medio de la tráquea, se propone resección traqueal con anastomosis terminoterminal, obteniendo resección completa, con seguimiento de 5 meses sin recurrencia, actualmente con tratamiento de quimioterapia a base de cisplatino/5-fluoracilo sobre cinco días cada tres semanas en principio por cuatro a seis ciclos. Discusión: Cuando existen dificultades para tratar el asma hay que buscar otros diagnósticos. El manejo de pacientes con carcinoma traqueal debe ser multidisciplinario (cirugía, radioterapia, quimioterapia), si es localizada y no hay invasión ganglionar (cirugía), cuando son más avanzados y resecables (radioterapia, un rol importante con quimioterapia). Los pacientes con este tipo de tumores, en particular todos los tumores traqueales, en general, deben ser referidos a centros con experiencia para el manejo de patología traqueal.

\section{1}

\section{Lesiones quísticas}

pulmonares y síndrome de Sjögren. Relato de caso
Florentín N, Cañete N, Pérez D

Dpto. Docencia INERAM

Introducción: El síndrome de Sjögren es una patología autoinmune crónica poco frecuente, caracterizada por infiltración linfocítica de tejido glandular y extraglandular, de afectación pulmonar variable. Presentamos un caso con afectación pulmonar específica visto en hospital de referencia. Relato de caso: Mujer de 60 años, sin comorbilidades aparentes, que cocina a leña desde la juventud. Consulta por dificultad para la deglución, síndrome seco y tos seca más dificultad respiratoria progresiva hasta moderados esfuerzos de 8 meses de evolución. Anti-Ro 341 UI/mL. Rx tórax: patrón reticulonodulillar bilateral no muy profuso. TAC de cortes finos de tórax: panalización predominantemente periférica, con distorsión de la arquitectura y estructuras quísticas bilaterales. Espirometría: CVF 57\%. TM6M: desatura 6\% (septiembre 2012). Inicia ciclofosfamida + predinsona. Siete meses después, disnea empeora; CVF 45\%. TM6M 509 m (desaturacion). Inicia azatioprina+prednisona+n-acetilcisteína. Seis meses después disnea estable, CVF 51\% TM6M 414 m (desaturación). Las imágenes tomográficas presentan un sostenido empeoramiento. No se realizó biopsia debido a compatibilidad clínicoimagenológica con neumonitis intersticial usual (UIP) secundaria a neumonitis intersticial linfoide (NIL). Discusión: La NIL es la menos frecuente de las neumonías intersticiales idiopáticas y es considerada dentro del espectro de enfermedades linfoproliferativas del pulmón. Predomina en mujeres. Al menos el $25 \%$ se asocia a síndrome Sjögren, siendo otras asociaciones: VIH, artritis reumatoide, lupus, virus Epstein- Barr y el HTLV-I. Se presenta a la TAC como vidrio esmerilado (100\%), espesamiento de septos interlobulares $(81 \%)$ y quistes $(68 \%)$. El caso presentado denota características iniciales de NIL con rápida evolución hacia UIP. Creemos que en este contexto la biopsia no es necesaria. El tratamiento es controversial y sustentado en series muy pequeñas.

22

Tuberculosis pulmonar en

\section{pacientes con diabetes mellitus}

Florentín N, Fusillo J, Cartes G, Gómez R, Román M, Pérez D

Dpto. Docencia INERAM

Introducción: Los pacientes con diabetes mellitus (DM) tienen tres veces más riesgo de contraer tuberculosis (TB) y tanto la presentación clínica, radiológica como la evolución y los resultados del tratamiento son peculiares. Presentamos un análisis preliminar de las características de esta asociación, vistas en el hospital de referencia. Material y métodos: Estudio observacional, caso-control de registros médicos, desde enero 2010 a enero 2014. Se incluyeron pacientes $>15 \mathrm{a}$ con TB+DM y tomaron al azar fichas con Dx de TB sin otras comorbilidades, consignando variables clínicas, radiológicas y mortalidad. Resultados: Veintiún casos de TB+DM (grupo A) vs. 21 casos control (grupo B) se analizaron. Edad media 53 $\pm 11 \mathrm{a} v s .31 \pm 14 \mathrm{a}$, respectivamente $(\mathrm{p}<$ $0.05)$. Sexo masculino $48 \%$ en el grupo A vs. $71 \%$ en grupo B ( $p>0.05)$. No se constataron diferencias significativas en la presentación clínica, radiológica ni en la mortalidad de esta muestra en particular. Discusión: En países en vías de desarrollo, la adherencia al tratamiento de enfermedades crónicas es menor y eso supone desenlaces diferenciados. Aunque en nuestra muestra y aún sin emparejamiento del grupo control no se han encontrado outcomes particulares; en estudios con mayor número de pacientes se observa que las manifestaciones clínicas son más severas, existe retardo en la conversión del esputo y mayor probabilidad de desenlaces desfavorables. Se imponen estudios de mayor envergadura.

\section{3}

Síndrome de Poland: Relato de caso

Florentín N, Rodríguez S, Peralta M, Román M, Pérez D

Dpto. Docencia INERAM 
Introducción: El síndrome de Poland corresponde a una alteración congénita poco frecuente caracterizada por la ausencia o hipoplasia del músculo pectoral mayor, que suele estar asociada a anormalidades de la extremidad superior ipsilateral. El objetivo de este trabajo es presentar el primer caso reportado en la literatura nacional y describir hallazgos encontrados en el paciente. Relato de caso: Varón de 39 años de edad, ex fumador con antecedente de tuberculosis pulmonar hace tres años. Consulta por síndrome bronquial obstructivo. Al examen físico presenta tórax asimétrico a expensas de agenesia del músculo pectoral mayor y menor del lado izquierdo e hipoplasia de la areola y del pezón ipsilateral. El paciente no presenta limitaciones funcionales importantes. Los estudios de imagen corroboran la ausencia de los músculos mencionados. Discusión: En el año 1841 Alfred Poland describe la ausencia unilateral de pectoral mayor, serrato anterior y oblicuo externo abdominal, asociado a sindactilia ipsilateral, y publica tal caso en la revista Guy's Hospital Reports con el título de Deficiencia del músculo pectoral. El caso aquí relatado no presenta las alteraciones digitales que se mencionan en varios reportes, aunque existen variantes de las formas clásicas. La etiopatogenia exacta se desconoce. Aunque el impacto estético es notorio, la terapéutica plástica raras veces es necesaria.

\section{4 \\ Divertículo traqueal: Relato de caso}

\section{Fretes J, Coronel R, Chaparro G}

Dpto. Docencia INERAM

Introducción: Los divertículos traqueales son una afección rara. Habitualmente se diagnostican de forma incidental como un hallazgo en una tomografía computarizada de tórax o en una fibrobroncoscopia. Presentamos un caso visto en el servicio. Descripción del caso: Paciente de sexo masculino de 45 años de edad, sin antecedentes de salud. Acude por cuadro de dos años de evolución de disnea a grandes esfuerzos, chillido de pecho y sensación de opresión a nivel de garganta; en consultorio externo se solicita TAC simple de tórax en donde se observa solución de continuidad en la cara lateral derecha de la tráquea, razón por la que se solicita broncoscopia. Discusión: Los divertículos traqueales pueden ser de dos tipos: congénitos o adquiridos. Los congénitos se presentan como formaciones saculares que conectan con la tráquea mediante un istmo estrecho que en ocasiones puede no verse. Poseen las mismas características histológicas que la tráquea. Suelen ser de pequeño tamaño y pueden acompañarse de otras malformaciones del árbol traqueobronquial. Tanto en divertículos congénitos como en adquiridos, la localización más frecuente es la pared traqueal posterolateral derecha. El tratamiento de esta patología, cuando no es sintomática, es generalmente conservador, ya que se trata de una patología benigna.

\section{5}

\section{Cuerpo extraño: Gasa en lecho quirúrgico de traqueostomía}

\section{Fretes J, Coronel R, Chaparro G}

\section{Dpto. Docencia INERAM}

La presencia de un cuerpo extraño en vías aéreas es infrecuente en adultos. Presentamos un caso llamativo visto en centro de referencia. Presentamos el caso de un paciente masculino de 33 años de edad con antecedente de trauma cráneo encefálico severo por accidente de motocicleta con ingreso UTI, requiriendo traqueostomía por intubación prolongada. Remitido al servicio ya sin traqueostomía por cuadro, un mes de disnea y estridor laríngeo. Se procede a examen de vías aéreas y extracción de cuerpo extraño: gasa quirúrgica. En grandes series, los cuerpos extraños no asfixiantes en adultos más frecuentes son fragmentos de hueso o piezas dentarias. En este caso, la primera sospecha fue de un granuloma postintubación, aunque en la literatura se describen, además, fragmentos del tubo o del introductor como causas de obstrucción posterior a traqueostomía. Los síntomas se resolvieron.
26

Prueba de

broncoprovocación con solución hipertónica en asma bronquial

\author{
Fretes J, Gaona M, Sosa L, Peralta \\ $M$, Rodríguez $O$, Pérez D
}

Dpto. Docencia INERAM

Introducción: No existen trabajos en nuestro país que investiguen alternativas a los clásicos broncoconstrictores (metacolina, carbacol, histamina, etc.) para pruebas diagnósticas en los asmáticos. Con el objetivo de evaluar la rentabilidad diagnóstica de la solución salina hipertónica diseñamos el siguiente ensayo. Material y métodos: Estudio observacional descriptivo de grupo de pacientes asmáticos e individuos aparentemente sanos. Se firmó consentimiento informado. Se excluyeron asmáticos con crisis recientes (> 3 semanas). Se utilizó solución hipertónica en crecientes concentraciones (1.8, 3.6 y $7.2 \% \mathrm{mmol} / \mathrm{L})$. Nebulizador ultrasónico con flujo $8 \mathrm{~L} / \mathrm{min}$. Las pruebas fueron efectuadas por profesional médico en sala de urgencia con equipamiento disponible para eventuales complicaciones. Se realizaron pruebas espirométricas (Easy on-PC v1.3.18 ndd ${ }^{\circledR}$ ). Protocolo: 1- Realización de espirómetro basal (si $\mathrm{VEF}_{1}<$ 70\%: paciente excluido); 2-inhalación de aerosol nebulizado de solución salina de $1.8 \%$ (5 inspiraciones profundas, lentas y sostenidas); 3) intervalo de 60 segundos; 4) maniobra espiratoria forzada (espirometría) para verificar $\mathrm{VEF}_{1}$; 5) $\mathrm{Si} \mathrm{FEV}_{1}$ $>80 \%$ de $\mathrm{VEF}_{1}$ basal se continúan pasos 2 al 4 hasta $\mathrm{VEF}_{1}<80 \%$ basal. Caída $>$ $20 \% \mathrm{VEF}_{1}$ basal se consideró positiva. Al finalizar test, broncodilatador rutinario. Resultados: Se incluyeron 20 pacientes (20 asmáticos y 20 individuos aparentemente sanos emparejados demográficamente. Esto es: $70 \%$ mujeres, promedio de edad 25 años, $70 \mathrm{~kg}, 1.65 \mathrm{~cm}$ de estatura, $\left.\mathrm{VEF}_{1} 89 \mathrm{~L} / \mathrm{s}\right)$. Se encontró que en $70 \%$ de los asmáticos la prueba broncoconstrictora (PBC) resultó positiva en comparación a $20 \%$ de los controles. (s70\%, e80\%, vpp77\% y vpn $72 \%$ ). El $30 \%$ de los as- 
máticos presentó positividad a la solución $7.2 \%, 20 \%$ lo presentó a $3.6 \%$ y el $20 \%$ a $1.8 \%$. La mayoría presentó tos después de las pruebas. Sólo un paciente presentó broncoespasmo intenso después de solución $7.2 \%$ pero que cedió con $\mathrm{Bd}$. El $30 \%$ de los asmáticos no presentó positividad al test. Discusión: La prevalencia de hiperreactividad bronquial en pacientes con síntomas de asma varía entre 52 y $100 \%$. Por el contrario, sólo del 47 al $75 \%$ de los pacientes con hiperactividad bronquial tienen asma. La PBC con salina hipertónica se mostró con errática sensibilidad en nuestra pequeña muestra y hay que señalar que no está exenta de riesgos.

\section{7 Detección de fumadores con el autorreporte y medición de $\mathrm{CO}$ exhalado}

\section{Giménez S, Miltos $P$, San Martín V, Calderoli F, Pérez D}

Cátedra Neumología -Hospital ClínicasFCMUNA

Introducción: Los estudios epidemiológicos evalúan el consumo de productos de tabaco en la población generalmente mediante un cuestionario anónimo con autorreporte, aunque esto puede llevar a respuestas inexactas. La medición de monóxido de carbono exhalado (MCE) es un método no invasivo para evaluar el consumo de tabaco. Este estudio busca comparar las mediciones de MCE con las respuestas a un cuestionario sobre consumo de tabaco. Material y métodos: Para el estudio fue empleada una muestra reclutada de manera oportunista de 105 personas. A todos se les ha realizado un cuestionario anónimo con autorreporte de tabaquismo y pruebas de MCE. Resultados: Del total de participantes $58(55.3 \%)$ fueron hombres y 47 (44.7\%) mujeres. La edad media fue de 19 años. Un total de 55 reportaron ser fumadores. La media de los niveles de MCE fueron 7 ppm para fumadores y 3 ppm para los no fumadores. Del grupo con autorreporte no Fumador el $20 \%$ tuvo MCE $\geq 5$ ppm. Del grupo con autorreporte Fumador el 52\% tuvo MCE $\geq 5$ ppm. De los fumadores según auto- rreporte 22 (40\%) tenían MCE por debajo de 5 ppm. Discusión: Un $60 \%$ de los que se reportaron fumadores dio positivo a la prueba. Los resultados negativos se relacionan con la ausencia de tabaquismo en las últimas 12 horas. De los no fumadores según autorreporte, 10 (20\%) dieron positivo. Esta discrepancia puede relacionarse a tabaquismo de segunda mano o falsa negación de tabaquismo. Conclusiones: Los estudios epidemiológicos deben utilizar marcadores bioquímicos para validar las respuestas a encuestas de tabaquismo. La confianza en los resultados se refuerza según el nivel de acuerdo entre MCE y el autorreporte.

\section{8}

\section{El «step test» o prueba del escalón como auxiliar diagnóstico en el asma}

\section{Godoy V, Fusillo J, Chaparro G, Silvero G, Pérez D}

\section{Dpto. Docencia INERAM}

Introducción: La presencia de limitación variable al flujo aéreo (LVFA) debe ser sumada a la probabilidad clínica para el diagnóstico de asma bronquial (GINA 2014). En nuestro medio, no se realizan con frecuencia las pruebas de broncoprovocación y mucho menos el reto bronquial con ejercicio (cicloergometría, banda sin fin o hiperventilación voluntaria eucápnica). Diseñamos este estudio con el objetivo de evaluar el desempeño de una prueba simple (step test) como reto bronquial en el asma. Material y métodos: En un estudio observacional; estudiantes de un colegio urbano fueron seleccionados para realizarlo. Los estudiantes fueron identificados por cuestionario estructurado y validado (Universidad de Alabama) completado por los padres o tutores, luego de firmar consentimiento informado. Se excluyeron a adolescentes con antecedentes médicos de interés. Las pruebas se llevaron a cabo en las instalaciones del colegio durante octubre y noviembre de 2012. Se incluyeron los pacientes con sospecha de asma. Inicialmente se realizó prueba de espirometría (referencias de Polgar) antes del ejercicio (Easy On-PC, ndd $^{\circledR}$ ). Step test: altura del peldaño $25 \mathrm{~cm}$ si altura adolescente $>137$ $\mathrm{cm}$; nivel de intensidad mantenida durante 5 min con target frecuencia cardíaca 150 a $200 \times$ min monitorizado con oximetría de pulso $\left(\mathrm{MF} 417^{\circledR}\right)$; metrónomo programado a 134-166 pasos/min. Seguidamente se realizaron pruebas espirométricas a los 3 y a los 10 min después de finalizar el ejercicio. Se consideró prueba positiva si disminución $>15 \%$ de $\mathrm{VEF}_{1}$ basal. Resultados: Todos los cuestionarios de 96 estudiantes fueron respondidos. Sesenta y seis $(68 \%)$ fueron clasificados como no asmáticos, $5(5,2 \%)$ ya tenían Dx de asma y 25 (26\%) estudiantes como probables asmáticos. De este último grupo, 23 accedieron a realizar la prueba (promedio: 13 años, $156 \mathrm{~cm}$ y $55 \mathrm{~kg}$ ). Apenas 2 mostraron una caída significativa del $\mathrm{VEF}_{1}$ (step test + ), uno a los 3 min y otro a los $10 \mathrm{~min}$. No hubo complicaciones. Discusión: El desempeño diagnóstico del step test es inferior a lo relatado para la prueba de ejercicio en general (banda sin fin o cicloergometría) en la muestra aquí estudiada. Sería interesante evaluar otros puntos de corte y optimizar los comparativos referentes.

\section{9 \\ Estudio sobre la $\mathrm{Pi}_{\max }$ en pacientes obesos y en pacientes con EPOC}

\section{González S, Palacios Z, Pérez D}

\section{Dpto. Docencia INERAM}

Introducción: Una prueba rápida y no invasiva que sirve para evaluar la fuerza muscular respiratoria es la presión inspiratoria máxima $\left(\mathrm{Pi}_{\max }\right)$. Desconocemos cuáles ecuaciones ajustan a valores de nuestra población. Hemos elaborado este estudio con el objetivo de analizar los valores y los ajustes de $\mathrm{Pi}_{\text {max }}$ a previstos usuales en diferentes grupos. Material y métodos: Estudio observacional en dos fases: a) comparación de $\mathrm{Pi}_{\text {max }}$ obtenida en pacientes con EPOC vs. individuos control emparejados y b) análisis de ajuste de $\mathrm{Pi}_{\max }$ obtenida en obesos. Los dos estudios se hicieron en períodos diferentes. Para la medición se empleó manómetro 
de presión negativa Smiths Medical ${ }^{\circledR}$ y previstos de Black-Hyatt $(\mathrm{H}=104-0.51 x E$; $\mathrm{M}=153-0.55 \mathrm{xE}$; ARRD,1969) y Costa $(\mathrm{H}=232.37-1.241 \mathrm{xE} ; \mathrm{M}=74.25-0.46 x \mathrm{x}$; J Pneumol, 2010). Técnica: ATS/ERS 2002. Análisis estadístico: graph instat ${ }^{\circledR}$ 2010. Resultados: a) EPOC vs. controles emparejados: Se incluyeron 15 pacientes del sexo masculino con EPOC (GOLDIII y GOLDIV) clínicamente estables y 15 adultos mayores (control emparejado, sin neumopatías); antropometría: $65.7 \pm 4.7 \mathrm{a}$; $20.9 \pm 2 \mathrm{~kg} / \mathrm{cm}^{2}$ y $65.4 \pm 4.6 \mathrm{a} ; 27.9 \pm 3$ $\mathrm{kg} / \mathrm{cm}^{2}$, respectivamente, IMC: < 0.05; Mediciones $\left(\mathrm{cmH}_{2} \mathrm{O}\right)$ : Grupo EPOC = $\mathrm{DPi}_{\text {maxBlack-Hyatt }}=43.3 \mathrm{y} \mathrm{DPi}_{\text {maxCosta }}=87.6 \mathrm{y}$ Grupo control (adultos mayores): $\mathrm{DPi}_{\text {max- }}$ Black-Hyatt $=11.3$ y DPi $_{\text {maxCosta }}=55(\mathrm{p}<0.01$ intergrupo); b) En obesos: Se incluyeron 15 pacientes del sexo masculino $(34 \pm 11$ años, $40.4 \pm 6.4 \mathrm{~kg} / \mathrm{cm}^{2}$ ) y 15 sexo femenino $\left(34.4 \pm 7.6\right.$ años, $\left.38.2 \pm 5.5 \mathrm{~kg} / \mathrm{cm}^{2}\right)$, sin antecedentes de enfermedades o síntomas respiratorios. En el grupo de los hombres $33 \%$ tenían obesidad clase III y entre las mujeres 53\%. El 80\% (n 12) de los individuos (de cada grupo) presentó valores por debajo de lo previsto ( $\mathrm{DPi}_{\text {maxBlack-Hyatt }}=39.4$ $\pm 19.31 \mathrm{cmH}_{2} \mathrm{O}$. Conclusiones: 1) la $\mathrm{Pi}_{\text {max }}$ de los pacientes con EPOC (GOLDIII y IV) aquí estudiados fue menor a los previstos por la ecuación de Black-Hyatt y de Costa; 2) la $\mathrm{Pi}_{\text {max }}$ de los EPOC $<$ a los controles; 3 ) la variación intraindividual de la $\mathrm{Pi}_{\text {max }}(11.2 \%)$ se ajusta a los previstos de Black-Hyatt en los adultos mayores de este estudio; 3) el DPi $i_{\text {maxcosta }}$ es mayor en los EPOC y en los adultos mayores; 4) existe una disminución de la presión inspiratoria en la mayoría de los obesos estudiados aquí.

\section{0 \\ Hipertensión pulmonar tromboembólica crónica}

\section{Guerreiro L, Pavetti F, Aguayo D, Martínez N, Quintana M, Pérez D}

Dpto. Docencia INERAM

Introducción: La hipertensión pulmonar tromboembólica crónica (HPTC), se define como persistencia de la presión media de arteria pulmonar $>25 \mathrm{mmHG}>$ seis meses después de un evento agudo. Es una complicación seria que ocurre hasta 2-4\% después de una embolia pulmonar. Es frecuente el retardo diagnóstico. Presentamos un caso visto en INERAM. Relato de caso: Varón de 62 años sin comorbilidades aparentes, con antecedente de accidente de lesión traumática en miembro inferior derecho durante accidente de tránsito con motocicleta hace 20 años. Consulta por disnea progresiva de dos años de evolución. Estudios previos: ecocardio: hipertrofia severa de ventrículo derecho e hipertensión pulmonar severa (PSAP $60 \mathrm{mmHg}$ ). TAC tórax: informada como normal. Remitido a INERAM por disnea en reposo, tendencia a la hipertensión, taquicárdico, polipneico. Analítica: Hgb 18g\%; HIV(-); gasometría arterial: $\mathrm{pH}$ de 7.44, $\mathrm{pCO}_{2}$ de $22.2 \mathrm{mmHg}, \mathrm{HCO} 315.0$ $\mathrm{mmol} / \mathrm{L}, \mathrm{EB}-6.6 \mathrm{mmol} / \mathrm{L}, \mathrm{pO} 264.4$ $\mathrm{mmHg}$, con una SatO 92.9\%. ProBNP: 3553 pg/mL. ECG. S1Q3T3, AngioTAC: defectos de relleno en paredes de tronco y ramas principales con calcificación de paredes (trombos murales), dilatación de tronco arteria pulmonar $(67 \mathrm{~mm})$. Ecocardiografía: dilatación e hipertrofia de cavidades derechas, hipertensión pulmonar severa (PSAP:127 mmHg), trombo en arteria pulmonar. Anticoagulación. Paciente estable. No se realizó tratamiento quirúrgico específico (tromboendarterectomía). Discusión: La HPTC es una enfermedad rara y probablemente éste es el primer caso descrito y presentado en nuestro país. En varias series los pacientes con esta condición demostraron alta prevalencia de enfermedades protrombóticas (deficiencia de prot C, prot S, Factor Leyden, ATIII, etc.). Aún no existen en nuestro país condiciones para el tratamiento quirúrgico de la HPTC; no obstante, en los países circunvecinos la experiencia ya ha comenzado.

\section{1}

Abordaje terapéutico de las fístulas broncopleurales: serie de casos

\section{Irazusta O, Agüero A, Guggiari R, Chaparro G, Pérez D}

Dpto. Docencia INERAM
Introducción: La fístula broncopleural (FBP) consiste en la comunicación del espacio pleural con el árbol bronquial. El objetivo de este reporte de casos fue examinar las diferentes opciones terapéuticas instauradas en servicio de referencia en cada caso. Descripción de la serie: Caso 1: Mujer 37 años con pulmón secuelar de TB: hemoptisis a repetición. Se decide lobectomía superior izquierda. Al 5to. día postoperatorio: secreción purulenta de bronquio fuente izquierdo y FBP. Se procede a inyección de sangre autóloga en dos sesiones de broncoscopia flexible. Después de largo período de internación (71 días) y progresiva mejoría (antibióticos y tubo de toracostomía con aspiración continua), la paciente es dada de alta; Caso 2: Varón de 22 años, portador de bronquiectasia lobar inferior secuelar a neumonía comunitaria, que consulta por hemoptisis en varios episodios, más fiebre. Neumonectomía. 5to. día posoperatorio: hidroneumotórax (Pseudomonas fluorescens). Broncoscopia: fístula del muñón, tres sesiones sin resolución (sangre autóloga y cera de hueso). Toracotomía: sutura sin éxito, cianoacrilato más esponja de gelatina. Control endoscópico: fístula resuelta. Alta. Caso 3: Mujer de 14 años, pulmón secuelar de $\mathrm{TB}$, infecciones a repetición, remitida a servicio por empiema por Acinetobacter baumanii. Después de mejoría: TAC tórax revela bronquiectasias localizadas, reiteradas. Lobectomía medio-basal derecha. Posoperatorio: fístula. Tres sesiones endoscópicas (espuma de gelatina y sangre autóloga). Cuarta broncoscopia para control: cierre fístula. Alta. Discusión: En la serie presentada aquí, las FBP son todas posquirúrgicas y como regla había infección concomitante. Las recomendaciones para el abordaje endoscópico son: fístulas $<5 \mathrm{~mm}$ y distales y los resultados terapéuticos son variables (30\%), requiriéndose a veces reiteradas sesiones. Relatos en literatura sobre material utilizado: etanol, polietilenglicol, cianoacrilato, fibrina, sangre autóloga, espuma de gelatina reabsorbible, instilación antibióticos, celulosa, cera de hueso, albumina-glutaraldehído. La alternativa eficaz es la cirugía en la mayoría de los casos. El soporte nutricional y los antibióticos son de vital importancia. La 
FBP continúa siendo una complicación grave de la resección pulmonar, con una mortalidad entre $19.5 \%$ a $71.2 \%$ según la literatura.

\section{2 \\ Secuestro pulmonar: relato de caso}

\section{Irazusta $\boldsymbol{O}$, Campuzano D, Palacios $Z$, Cartes G}

Dpto. Docencia INERAM

Introducción: El secuestro pulmonar es una masa de tejido pulmonar que no se comunica con la vía respiratoria central y que recibe su aporte sanguíneo a través de la circulación sistémica. Presentamos un caso visto en un hospital de referencia. Descripción del caso: Varón de 46 años, trasplante renal hace tres años en uso de micofenolato, tacrolimus y prednisona que queda hospitalizado por cuadro recidivante de hemoptisis. Signos vitales estables. Roncus difusos en base de pulmón izquierdo. Analítica de interés: glicemia $135 \mathrm{~g} / \mathrm{dL}$, creatinina: $1.1 \mathrm{~g} /$ dL. Baciloscopias negativas. TAC tórax: opacidad basal paravertebral izquierda. Broncofibroscopia: escaso sangrado y secreción purulenta en B10 izq. AngioTAC tórax: opacidad paravertebral que recibe ramas arteriales tributarias de las bronquiales, que sugiere secuestro lobar inferior izquierdo. Toracotomía: lobectomía inferior izquierda. Anatomía patológica: Secuestro pulmonar. Discusión: En una gran serie $(n=42)$, el $23 \%$ de los pacientes con secuestro consultaron por hemoptisis a repetición, como aconteció con el caso aquí ilustrado. El diagnóstico de esta enfermedad se basa en la demostración de la arteria sistémica aberrante que irriga al segmento de parénquima pulmonar no funcionante (tomografía axial computada con contraste endovenoso o angio-TAC y la resonancia nuclear magnética o la ecografía con Doppler). Aunque más del $60 \%$ de los pacientes con secuestro pulmonar extralobar coexisten con anomalías congénitas como hipoplasia, malformación adenomatoide quística o quiste broncogénico, no es frecuente su asociación con anormalidades congénitas de otros órganos, hay relatos de asociación con aplasia renal o con nefromas quísticos.

\section{3}

\section{Absceso pulmonar: Serie de casos \\ Irazusta O, Pratt J, Roman M, Pérez D}

Dpto. Docencia INERAM

Introducción: Los abscesos pulmonares son cavidades en el parénquima pulmonar con acumulación de tejido pulmonar necrosado y pus en su interior, causadas por agentes microbianos. El objetivo del trabajo es describir características clínicas de los casos vistos en hospital de referencia. Material y métodos: Estudio observacional, descriptivo de registros médicos de pacientes con diagnóstico de absceso pulmonar estudiados en servicio de referencia desde enero-2009 hasta diciembre-2013. Se excluyeron pacientes < 18 años y se consignaron variables clínicas y terapéuticas. Resultados: 23 pacientes (16 hombres) fueron incluidos, con edad promedio de 44 años (rango 20-74). Motivo de consulta: hemoptisis $35 \%$, dolor torácico $22 \%$ y fiebre $17 \%$. La duración promedio de síntomas: 41 días (rango 3-150) y las comorbilidades consignadas fueron: etilismo 52\%, tabaquismo $43 \%$, diabetes mellitus $17 \%$, epilepsia $13 \%$. El $48 \%$ refería uso previo de antibióticos antes de la consulta. En el $56 \%$ no se obtuvo desarrollo de gérmenes patógenos, en el 13\% creció Staphylococcus aureus (quizás valga la pena mencionar los otros gérmenes). BAAR en esputo y Test rápido para HIV negativos en todos los casos. La afectación radiológica denotó afección medial o basal en $69 \%$ de los casos. Se utilizó ampicilina sulbactam más otro antibiótico en $43 \%$ de los casos y ceftriaxona más clindamicina en $30 \%$. El promedio de días de internación fue de 19 (rango 7-33) y en $87 \%$ se constató cura. El $13 \%$ abandonó terapéutica. Discusión: En esta serie llama la atención lo prolongado de los síntomas antes de la consulta. Importante frecuencia de comorbilidades. La baja rentabilidad microbiológica probablemente se debe a uso previo de antibióticos, ya que rutinariamente no disponemos de cultivos para anaerobios. El tratamiento médico (antibiótico) conlleva usualmente desenlaces satisfactorios pese al drop-out consignado.

34

\section{Espirometría en adultos mayores. Un análisis crítico}

Martínez H, Ojeda M, Pérez D

Introducción: La literatura neumológica internacional actualmente dispone de pocos datos sobre los valores espirométricos de referencia en la población $>80$ años. El objetivo de este estudio es comparar los valores previstos por ecuaciones de los valores obtenidos en individuos mayores de 80 años de nuestro país. Material y métodos: Mediante un estudio observacional se efectuó espirometría forzada en una muestra poblacional de adultos mayores sanos, que nunca fumaron, se compararon los valores obtenidos a las ecuaciones de referencia de Crapo, Knudson, Enright y Arnold (Caucásico), Pereira, Pérez-Padilla (PLATINO) y el GLI (Global Lungs Initiatives). Se consideró buen ajuste cuando dicha diferencia fue menor de $100 \mathrm{~mL}$. Para analizar la diferencia estadística entre el valor medido y el valor esperado se utilizó prueba t para muestras relacionadas. Resultados: 27 adultos mayores (13 del sexo masculino, edad $82.5 \pm 2.7$ años, $\mathrm{h}=165.7 \pm 5.26 \mathrm{~cm}$ y 14 mujeres, edad $83.9 \pm 3.7$ años y $\mathrm{h}=$ $156.4 \pm 5.95 \mathrm{~cm}$ ), realizaron maniobras espiratorias forzadas de buena calidad. Se constataron diferencias dispares (> $100 \mathrm{~mL}$ ) entre los valores esperados de capacidad vital forzada (CVF) y volumen espiratorio forzado en un segundo $\left(\mathrm{VEF}_{1}\right)$ y los observados. Test de Student: $\mathrm{p}>0.05$. El LIN de la tasa $\mathrm{VEF}_{1} / \mathrm{CV}$ es de 60 para hombres y mujeres según Pérez-Padilla. A excepción de valores esperados para CVF en mujeres, los previstos por el GLI apuntan a valores inferiores importantes. Conclusión: La aplicación de ecuaciones de predicción derivadas a partir de adultos 
más jóvenes puede ser inapropiada debido a la relación entre la función pulmonar con la edad, o a que la altura podría cambiar en etapas avanzadas de la vida. Probablemente el tamaño pequeño de la muestra explica la ausencia de hallazgos estadísticamente significativos, pero nótese que el LIN de la tasa $\mathrm{VEF}_{1} / \mathrm{CVF}$ prevista es mucho menor al punto de corte fijo del GOLD para diagnóstico de EPOC. El GLI no atenúa la problemática de los hiatos. Palabras clave: Espirometría, valores de referencia, adultos mayores.

\section{5 \\ Síndrome hipereosinofílico asociado a FIP1L1/PDGFR: Reporte de caso}

\section{Martínez N, Aguayo D, Ferreira Nizza $R$}

Dpto. Docencia INERAM

Introducción: El síndrome hipereosinofílico asociado a FIP1L1/PDGFR (SHE-FP) constituye apenas entre el 11-14\% de los síndromes eosinofílicos. El compromiso pleuropulmonar es infrecuente. Presentamos un caso visto en hospital de referencia. Descripción de la serie: Varón de 51 años, constructor, diabético, con dos internaciones anteriores por derrame pleural cuya causa no pudo determinarse. Consulta por disnea progresiva y dolor torácico base hemitórax derecho de dos años de evolución, más pérdida importante de peso. Hemograma: leucocitos $8,400 / \mathrm{mm}^{3}$ (E: 14\%). TAC tórax: derrame pleural a derecha y pequeñas opacidades intersticiales bilaterales. Mielograma: infiltración medular por eosinófilos de aspecto maduro. Estudios moleculares revelan translocación FIP1L1/PDGFR ALFA deleción intersticial de cromosoma 4q12, rasgo que implica sensibilidad a imatinib, medicamento que no existe en nuestro medio. Tratamiento: prednisona + hidroxiurea. Paciente mejora eosinofilia y aún en vigencia de los síntomas, es remitido a un Servicio de Oncohematología. Discusión: El SHE-FP ocurre casi exclusivamente en pacientes de sexo masculino y el compromiso pleuropulmonar comprende la tos crónica y/o hiperreactividad bronquial en ausencia de anormalidades radiológicas, hasta enfermedades restrictivas con opacidades pulmonares. Otros tejidos pueden afectarse: piel (frecuente), miocardio y nervioso. El abordaje multidisciplinario es fundamental para el manejo clínico.

\section{6}

\section{Variabilidad del pico flujo (flujo espiratorio máximo) en el asma bronquial}

\section{Molinas G, Álvarez O, Pérez D}

Dpto. Docencia INERAM

Introducción: Uno de los cambios radicales del GINA en cuanto al manejo del asma en los últimos tiempos, es la necesidad de consignar la presencia de limitación variable al flujo aéreo (LVFA). Entre otros métodos, la variabilidad del flujo espiratorio forzado o pico flujo (PF) es un método disponible y accesible. Evaluamos en este estudio dos diferentes conceptos de variabilidad y también dos diferentes puntos de corte en asmáticos. Material y métodos: Estudio observacional descriptivo de grupo de pacientes asmáticos e individuos aparentemente sanos, en quienes se midió el PF, de modo estandarizado y tres veces por día, durante una semana, previo entrenamiento de la técnica para cada participante. Para la realización de la prueba se utilizó un dispositivo Carefusion ${ }^{\circledR}(\mathrm{Mi}-$ croPeak TM - 2010), proporcionado a cada participante junto elementos para registrar los valores. Las fórmulas de variabilidad d PF se calcularon de dos formas: a- $\left[\left(\mathrm{PF}_{\max }{ }^{-}\right.\right.$ $\left.\left.\mathrm{PF}_{\text {min }}\right) / \mathrm{PF}_{\text {max }}\right]$ x100 y b- $\left[\left(\mathrm{PF}_{\text {max }}-\mathrm{PF}_{\text {min }}\right) / \mathrm{PF}\right.$ medio] x 100, resultantes del NHBLI y del GINA 2014, respectivamente. También se compararon dos puntos de corte de variabilidad: $20 \%$ NHBLI (D20) y $10 \%$ GINA (D10). Resultados: Se estudiaron 20 individuos (10 pacientes asmáticos y 10 individuos aparentemente sanos=grupo B). 5 varones y 5 mujeres en cada grupo. Características demográficas de los pacientes asmáticos: edad: $27 \pm 3.8$ años (ds), peso: $70.5 \pm 13.7 \mathrm{~kg}$, altura: $1.70 \pm$ 0.06 m e IMC: $24 \pm 2.9 \mathrm{~kg} / \mathrm{cm}^{2}$, sin diferencias significativas con grupo control.
No existió diferencias en la sensibilidad (80\%) al comparar las fórmulas de NHBLI y GINA si D10 (s90\%, e80\%, VPP 82\% y VPN 89\%); sin embargo si D20 sólo un paciente consignó positivo (fórmula GINA). Discusión: Aun en esta muestra pequeña y tomando el diagnóstico clínico de asma como gold standard, el punto de corte de $20 \%$ pierde (en relación a D10) en captar los verdaderos positivos. Estudios de mayor importancia donde se incluyan otras metodologías de acertar la LVFA, complementarían estos hallazgos.

\section{7 \\ Neumotórax bilateral secundario a neumatocele. Relato de caso}

\section{Medrano A, Fernández J, Silvero G, Pérez D}

Dpto. Docencia INERAM

Introducción: Los neumatoceles son espacios aéreos con pared fina contenidos dentro del parénquima pulmonar, que aparecen como complicación poco frecuente de la neumonía. Casos de neumotórax por ruptura de los quistes son escasamente (casos en Pubmed) relatados en la literatura. Relatamos un caso visto en el servicio. Descripción del caso: Varón de 15 años, sin comorbilidades conocidas, que posterior a traumatismo de hombro derecho queda con dolor, más fiebre de un mes de evolución. Dos semanas después de trauma, presenta expectoración verdosa y dificultad respiratoria. Acude a hospital donde se obtiene abundante cantidad de líquido de articulación afectada, siendo sometido a otros estudios. Ingresa a UCIA de la región con diagnósticos de neumonía adquirida en la comunidad y sepsis, iniciando tratamiento con meropenem y vancomicina. El cultivo de líquido articular informa Staphylococcus aureus meticilino-sensible. Debido a mala evolución, el paciente es trasladado a centro de referencia. Se suspende esquema antibiótico y se inicia oxacilina, ciprofloxacina y amikacina. Durante su tratamiento el paciente empeora bruscamente, disnea y la tomografía de nota neumotórax bilateral y presencia de quistes bilaterales. Se 
coloca tubo de drenaje sellado bajo agua con mejoría sustancial del cuadro global. El paciente evoluciona favorablemente y sus controles tomográficos muestran resolución total. Discusión: La incidencia de los neumatoceles es de $2-8 \%$ de todos los casos de neumonía en niños, pero puede ser de $85 \%$ en pacientes con neumonía estafilocóccica, según algunas series. La tomografía axial computada de tórax puede establecer el diagnóstico definitivo. Habitualmente no producen ningún síntoma adicional al proceso infeccioso subyacente y remiten espontáneamente. El caso aquí presentado representa una complicación poco frecuente, llamando la atención la asombrosa recuperación parenquimatosa.

\section{8 \\ Asma ocupacional: Un estudio clínico y funcional en peluqueras}

\section{Pavetti F, Silvero C, Fusillo J, Pérez D}

Dpto. Docencia INERAM

Introducción: No existen trabajos sobre asma ocupacional en el país. La literatura reporta asma bronquial en peluqueras debido a exposición a persulfato de amonio. Con el objetivo de investigar la frecuencia de síntomas respiratorios y evaluar la prueba de broncoprovocación específica en este grupo de trabajadores, hemos elaborado el siguiente estudio. Material y métodos: En un estudio observacional y transversal de muestras por conveniencia, se administró un cuestionario sobre síntomas respiratorios y se efectuó prueba de provocación bronquial específica (PBE) a un grupo de peluqueras. El cuestionario apuntó a conocimientos de riesgos laborales y presencia o no de síntomas relacionados a asma. En la fase de PBE sólo se incluyó a personas que firmaron el consentimiento informado. La Prueba se efectuó en el hospital y consistió en realizar una prueba espirométrica basal (Easy on-PC ndd $^{\circledR}$ ) y posterior exposición (10 min) a una bandeja ubicada a $30 \mathrm{~cm}$ que contenía 30 gramos de persulfato (polvo) mezclado con $50 \mathrm{~g}$ de lactosa. Subsecuentes medidas de $\mathrm{VEF}_{1}$ y CVF se realizaron cada 15 min durante la primera hora y a intervalos de 60 min en las 3 horas subsecuentes. Se consideró respuesta positiva si se constataba caída del $\mathrm{VEF}_{1}$ basal $>20 \%$. Se consignan las frecuencias de las variables cualitativas y cuantitativas. Resultados: 40 peluqueras (edad media = 28 años) respondieron al cuestionario y sólo 11 asintieron a participar de la PBE. Tiempo de exposición: 9 años, aproximadamente $10 \mathrm{~h}$ /día; de la muestra total: 16 (40\%) refirieron síntomas de asma (5 o $12.5 \%$ refirieron que los síntomas empeoraban en el trabajo). Ninguna conocía la asociación (persulfato-asma ocupacional) y sólo $4(10 \%)$ refería usar algún tipo de protección. Sólo 8 (ocho) trabajadoras con síntomas y 3 (tres) de las asintomáticas, accedieron a realizar la prueba. $\operatorname{PBE}(+)$. En dos de las sintomáticas (25\%), $\downarrow \mathrm{VEF}_{1}>$ $20 \%$ (una de ellas con insuficiencia respiratoria, recuperada con tratamiento y otra a las 2 h con síntomas leves). Discusión: Existió importante prevalencia de síntomas respiratorios y asma bronquial en la muestra de peluqueras aquí estudiada. Las pruebas de broncoprovocación conllevan riesgos en determinados individuos.

39

Valor diagnóstico de la PCR en tiempo real en la TB pulmonar

\section{Pavetti F, Gómez R, Román M, Pérez $D$}

\section{Dpto. Docencia INERAM}

Introducción: La tuberculosis es una enfermedad infectocontagiosa causada por el bacilo Mycobacterium tuberculosis. El diagnóstico de la tuberculosis requiere de la combinación de una serie de técnicas microbiológicas, histopatológicas y recientemente las moleculares. ${ }^{3}$ La detección temprana es esencial para reducir la tasa de mortalidad e interrumpir la transmisión. ${ }^{4}$ Este trabajo busca investigar la utilidad de una prueba introducida recientemente en nuestro país, que es la prueba de PCR en tiempo real conocida como GeneXpert ${ }^{\circledR}$. Objetivos: Determinar la sensibilidad y especificidad de la prueba de GeneXpert ${ }^{\circledR}$ para la detección precoz de la tuberculosis en pacientes internados y ambulatorios del Instituto Nacional de Enfermedades Respiratorias y del Ambiente. También determinar la eficacia de esta prueba para la detección de la resistencia a rifampicina. Materiales y métodos: Estudio observacional descriptivo de registros clínicos de pacientes adultos internados y ambulatorios que se sometieron a prueba de GeneXpert ${ }^{\circledR}$ entre enero y julio del 2014. Se seleccionaron los pacientes cuyos resultados fueron MTB detectados. A su vez, éstos se clasificaron en pacientes cuyo objetivo de la prueba era establecer el diagnóstico de tuberculosis y en pacientes en los que se buscaba resistencia a rifampicina. Resultados: $\mathrm{Se}$ solicitaron un total de 243 GeneXpert $^{\circledR}$ durante el período de enero de 2014 a julio de 2014, de los cuales se registraron 80 casos (32\%) de MTB detectados. Los casos de MTB detectados se dividieron en dos grupos: el primer grupo constituido por 31 casos, fueron los casos de GeneXpert $^{\circledR}$ solicitados para diagnóstico, y el segundo grupo constituido por 49 casos, que fueron las pruebas solicitadas para determinación de resistencia a rifampicina. La sensibilidad de la prueba de GeneXpert $^{\circledR}$ según nuestro análisis en el grupo de diagnóstico de tuberculosis es del $91 \%$ y la especificidad del $92 \%$, mientras que la sensibilidad y especificidad para la detección de la resistencia a rifampicina fue del 7 y $90 \%$, respectivamente. Conclusión: GeneXpert ${ }^{\circledR}$ MTB/RIF detecta casos de tuberculosis con mayor precisión y más rápido que la baciloscopia, y reduce significativamente la tasa de tratamiento empírico.

\section{0 \\ Mediastinitis necrotizante descendente: A propósito de cuatro casos}

Pavetti $F$, Núñez D, Ortiz A, Rodríguez S, Guggiari R, Pérez D

Dpto. Docencia INERAM

Introducción: La mediastinitis necrotizante descendente (MND) es una forma infrecuente de mediastinitis, que resulta de la diseminación de una infección cer- 
vical severa hacia los tejidos torácicos. La mortalidad varía entre $10-30 \%$. Presentamos una serie de cuatro casos vistos en hospital de referencia. Presentación de casos: Caso 1: Varón de 37 años, agricultor, tabaquista y etilista, consulta por fiebre de 6 días, más dolor torácico y dificultad respiratoria y tos productiva secundaria a foco odontogénico. Rápida evolución a insuficiencia respiratoria. TAC: mediastinitis. Dos intervenciones quirúrgicas (mediastinotomía cervical primero y toracotomía posterolateral derecha con intervalo de 7 días), sendos drenajes en ambos y cobertura antibiótica resultan en 62 días de internación y alta del paciente en buenas condiciones. Gammagrafía ósea craneal: osteomielitis maxilar inferior. Caso 2: Varón de 49 años, hipertenso, tabaquista y etilista, antecedente de ACV (2 años), remitido a nuestro servicio después de cuadro de 20 días de tos productiva y pérdida de peso. Portador de enfermedad periodontal crónica. Shock séptico. TAC tórax: neumomediastino y mediastinitis. Mediastinotomía cervical anterior y media más toracotomía posterolateral derecha en mismo acto quirúrgico. Drenajes. Complicaciones: absceso cerebral y fístula pleurocutánea. Antibióticos. Internado por 45 días, es dado de alta en buenas condiciones. Caso 3: Varón de 19 años, sin comorbilidades, odontalgia de 30 días de evolución. Shock séptico, insuficiencia respiratoria y pioneumotórax. TAC: mediastinitis. Remisión a INERAM. Caquéctico. Mediastinotomía cervical y toracotomía posterolateal derecha. Óbito. Caso 4: Varón de 20 años, inicia cuadro con odontalgia y adenoflemón cervical que resulta en MND (TAC). Cervicotomía y antibióticos. Después de semanas de internación es dado de alta. Discusión: En la serie presentada aquí llama la atención la buena evolución de varios casos al combinar efectivas medidas médico-quirúrgicas. Los desenlaces favorables devienen de un diagnóstico y tratamiento tardío. La rentabilidad microbiológica es frustrante al no disponer rutinariamente de cultivos para anaerobios y debido al uso previo de atb.

\section{1}

\section{Embolia grasa: Reporte de caso}

Quintana Y, Aquino M, García A, Quiñonez R, Pérez D

Dpto. Docencia INERAM-Sanatorio San Sebastián

Introducción: La embolia grasa se asocia, generalmente, con fractura de huesos largos y pelvis y muchas veces puede ser un caso subclínico. Existen casos reportados de insuficiencia respiratoria posterior a liposucción. Presentamos un caso muy ilustrativo visto en el servicio. Descripción del caso: Mujer de 26 años, alérgica a AINES que es internada en la Unidad de Cuidados Intensivos por dificultad respiratoria a mínimos esfuerzos, de inicio brusco más tos cianotizante y sensación febril con sudoración profusa. Antecedentes de interés: liposucción de $5 \mathrm{~h}$ de duración y rinoplastia realizadas $72 \mathrm{~h}$ antes de cuadro respiratorio. Analítica: hgb 9.9 g\%; GPT:33U/1 GOT:35U/1. K:3.3meq/L. Dímero D negativo. Gases arteriales: $\mathrm{pO}_{2}: 39$ torr, $\mathrm{pCO}_{2}$ : 32torr, Sat 74\%. ECG: taquicardia sinusal. Ecocardiograma: ventrículo derecho dilatado, movimiento asincrónico de septo interventricular, hipertensión pulmonar moderada a importante (PaS arteria pulmonar: $55 \mathrm{mmHg}$ ). AngioTAC pulmonar: negativo para TEP, importante derrame pleural bilateral. El contexto insuficiencia respiratoria posterior a liposucción prolongada propone el Dx. de embolia grasa. La paciente no fue intubada y presentó notable mejoría en los siguientes días con tratamiento de soporte. Ecocardiografía de control (3 días después, cifras de PSAP: $25 \mathrm{mmHg}$ ) normal. Paciente va de alta en buenas condiciones. Discusión: La embolia grasa puede ser de origen traumático (más frecuente) y no traumático (quemaduras, osteomielitis, pancreatitis, etc). Existen apenas 31 artículos sobre embolia grasa secundaria a liposucción en adultos en SciELO y Pubmed. Durante la liposucción, el daño mecánico afecta al tejido graso, a los tejidos blandos subyacentes y a los vasos sanguíneos, haciendo que la grasa ingrese a los vasos sanguíneos dañados. El valor diagnóstico del hallazgo de gotículas lipídicas en sangre o en lavado broncoalveolar es discutido. El criterio es clínico (Gurd, Schonfeld o Lindeque). En el caso relatado no constatamos síntomas neurológicos ni el rash petequial (20-50\% de los casos). Consignamos el escaso valor del dímero D y de la angiotac torácica como relatados en otros casos publicados.

42

\section{Micobacterias no tuberculosas en pacientes HIV (-): Serie de casos}

\section{Rodríguez M, Gómez R, Coronel R, Pérez D}

Dpto. Docencia INERAM

Introducción: La incidencia de infección por micobacterias no tuberculosas (MNT) ha aumentado significativamente en los últimos años en varios países. Describimos la primera serie de casos en el INERAM. Descripción de la serie: Caso 1: Varón, 50 años, recolector de basura, fumador, etilista, HIV (-), tratamiento previo para TB, consulta por cuadro catarral. Cavidades en TAC de tórax. Cultivo de esputo: Mycobacterium avium-intracellulare. Tratamiento: amicacina-ciprofloxacina-claritromicina. Sin seguimiento. Caso 2: Varón, 52 años, nativo originario (ayoreo), agricultor, fumador, etilista, HIV (-); TB pulmonar previa, consulta por cuadro catarral y disnea. Cavidades en radiografía, cultivo de esputo: Mycobacterium de crecimiento lento. Inicia claritro-cipro-etambutol, abandona al segundo mes. Reingresa al año por disnea en reposo. Cultivo y PCR: Mycobacterium avium-complex. Mejoría clínica y cultivo (-) al seguimiento. Caso 3: Varón, 65 años, agricultor, exfumador, etilista,HIV (-), fracaso de tratamiento con HRZE por seis meses. Siete meses después evolución tórpida, hemoptisis y disnea a moderados esfuerzos. TAC: Cavidades y bronquiectasias. Cultivo de esputo: Mycobacterium chelonae. Tratamiento con claritro-cipro-SMX.TMP. Actualmente asintomático. Caso 4: Mujer, 68 años, QHD, HIV (-); antecedente de abandono de tratamiento antibacilar. Dos años después por cuadro catarral, disnea, pérdida de peso. Cavidades y bronquiectasias a la Rx. Dos cultivos positivos para Mycobacterium abscessus. Tratamiento: amicacina, imipenem y claritromicina. 
Mejoría clínica y cultivo (-) al seguimiento. Caso 5): Mujer, 69 años, QHD, HIV (-), con cuadro catarral y pérdida de peso posterior a fracaso terapéutico antituberculoso. Cavidades en Rx. Cultivo esputo: Mycobacterium chelonae. Inicia claritromicina-etambutol, claritromicina. A seis meses mejoría clínica y cultivo (-). Discusión: La mayor incidencia de este tipo de infecciones es debido a la contribución de técnicas moleculares para el diagnóstico. La sospecha diagnóstica puede devenir del fracaso de tratamiento antituberculoso. Recordemos que un germen BAAR (+) puede no ser TB.

\section{3}

\section{La nariz electrónica como} un marcador sustituto de la respuesta al tratamiento de la tuberculosis pulmonar (protocolo ELNOSUR).

\section{Rodríguez M, González S, Coronel $R$, Romero N, Pérez D. Gerritsen JW, Bruins M, Gómez R, Yntema JB, Magis $C$}

Dpto. Docencia INERAM- Radboud University (Netherland)

Objetivos: 1. Determinar la exactitud diagnóstica de la nariz electrónica como un marcador sustituto de la respuesta al tratamiento en la tuberculosis (TB) pulmonar. 2. Explorar los factores que influyen en la exactitud de las narices electrónicas como un marcador sustituto de la respuesta en la tuberculosis pulmonar. Material: Diseño: Estudio observacional de 10 pacientes con TB confirmada (cultivo). Serán consignadas variables antropométricas y hábitos tóxicos del paciente. Criterios de inclusión: $>18$ años, acuerdo por consentimiento informado, capacidad para expectorar, no antecedente de tratamiento antibacilar en seis meses, internado en INERAM; Criterio de exclusión: dificultad para respirar dentro del dispositivo medidor (nariz electrónica). Tamaño muestral: 10 pacientes por tratarse de estudio piloto para ser utilizado como prueba de concepto. Instrumentos: El AENOSE ${ }^{\circledR}$ (eNOSE, BV, Zutphen, Holanda) o nariz electrónica es un dispositivo que mide la composición del aire mediante modulación térmica de la superficie de un sensor, pudiendo identificar un patrón de múltiples señales acorde a los compuestos volátiles detectados, utilizando la tecnología de ondas acústicas de superficie, polímeros conductores y sensores de óxidos metálicos. Lugar de estudio: Hospital de referencia; la recolección de muestras (clínica y aire exhalado) se realiza en una habitación designada. Estudios microbiológicos: Laboratorio del hospital de referencia. Los datos se analizan en la Universidad Radboud (Holanda). Métodos: A los pacientes diagnosticados con TB se les pide proporcionar semanalmente una muestra de aire exhalado por la $\mathrm{AENOSE}^{\circledR}$ durante cinco minutos. Esta muestra de aire se toma antes de comenzar el tratamiento y después cada semana durante el tratamiento normal. Al momento del diagnóstico y después semanalmente, se toma una muestra de esputo para la tinción y el cultivo. Se completa el formulario clínico del paciente. Estudio acorde a Declaración de Helsinki (2008) y buenas prácticas clínicas. Se firma consentimiento postinformado. Los análisis estadísticos se realizan acorde a test paramétricos o no paramétricos. El cronograma completo del estudio se extiende hasta diciembre de 2014.

\section{4}

Síntomas respiratorios y espirometría en cuidadores de aves

\section{Rodríguez S, Fusillo J, Florentín N, Silvero $G$, Pavetti F, Pérez D}

\section{Dpto. Docencia INERAM}

Introducción: Existe escasos trabajos nacionales sobre enfermedades ocupacionales. La neumonitis por hipersensibilidad, la psitacosis y el asma ocupacional son eventualidades en los cuidadores de aves. Este ensayo se realizó con el objetivo de investigar la prevalencia de síntomas respiratorios y su posible repercusión funcional en un grupo de trabajadores. Material y métodos: Estudio observacional y descriptivo de un grupo de cuidadores de aves mediante cuestionario estructurado y medición de variables espirométricas. Se excluyeron pacientes conocidos portadores de asma u otras enfermedades pulmonares. Se firmó un consentimiento informado previo a la participación. Resultados: De 42 personas cuidadoras de aves se seleccionaron 7 trabajadores de sexo masculino y 3 de sexo femenino cuya edad promedio fue de 34.6 años; el peso promedio $73.1 \mathrm{~kg}$; la talla promedio 167.1 y el índice de masa corporal promedio 23.84. El cuestionario denotó que de este grupo $40 \%$ refería chillido de pecho, $40 \%$ expectoración, disnea a moderados esfuerzos: $30 \%$, rinorrea $30 \%$, tos $20 \%$ y $10 \%$ dolor torácico. Comorbilidades: obesidad $2 \%$, tabaquismo $2 \%$. Hallazgos espirométricos: aunque la tasa $\mathrm{VEF}_{1} / \mathrm{CVF}$ post $\mathrm{BD}$ fue normal en todos, se constató valores inferiores al LIN en cuatro casos (40\%) en las maniobras pre BD y respuesta significativa en dos de ellos en $\mathrm{VEF}_{1}$ post $\mathrm{BD}$. Discusión: Se constata importante tasa de prevalencia de síntomas respiratorios (40\% de asma ocupacional) en la muestra aquí analizada. Estudios longitudinales, con mayor número de individuos y con recursos de tomografía esclarecerían aún más los hallazgos en esta línea de investigación que es pionera en nuestro país.

\section{5}

\section{Hipertensión pulmonar asociada a sarcoidosis}

\section{Rolin P, Olmedo C, Benítez S, Aguayo $D$, Pérez D}

Dpto. Docencia INERAM

Introducción: La hipertensión pulmonar (HP) es una complicación cuya prevalencia es controversial en la sarcoidosis, pero que conlleva un pronóstico pobre. Presentamos un caso visto en el servicio. Descripción del caso: Mujer de 59 años, hipertensa de larga data, disnea progresiva de 10 años de evolución, dedos en palillo de tambor, crepitantes bilaterales basales, Dx de sarcoidosis (biopsia transbronquial) dos años antes de consulta. Signos vitales: Fr: 28xmin. Rx tórax: opacidades reticulonodulillares bilaterales basales. TAC tórax: panalización bilateral. Ergometría: negativo para isquemia. CVF: $70 \%$. $\mathrm{paO}_{2}$ : 
$62.5 \mathrm{mmHg}, \mathrm{SatO}_{2}: 92 \%$ (FiO2: 21\%). Primera y segunda ecocardiografías: (PSAP $67 \mathrm{mmHg}$ y $81 \mathrm{mmHg}$ ), leve hipertrofia ventricular izquierda y FE: 74\%. Doppler mmii: (-). Dímero D: (-). Dx: Sarcoidosis estadio IV e hipertensión pulmonar. Inicia azatioprina y prednisona. Seis meses después, refiere mejoría de disnea. Ecocardiografía: PSAP: 25 mmHg, FE: 70\%. Paciente permanece estable por tres meses más, luego abandona tratamiento: disnea empeora, paciente no desea tratamiento. Discusión: La decisión de tratamiento fue tomada en la época (2005) porque no disponíamos de los vasodilatadores y la paciente clamaba por terapéutica. Resulta llamativa la respuesta terapéutica. La obliteración vascular por la fibrosis pulmonar, una vasculitis granulomatosa, una venopatía oclusiva o la liberación de factores vasoactivos, son postuladas como las causas de HP asociada a sarcoidosis. Los casos relatados en la literatura y que respondieron a inmunosupresores no pertenecían a estadío IV.

\section{6}

\section{Afectación diseminada por Rhodococcus}

\section{Rolin P, Pavetti F, Benítez S, Núñez $D$, Pérez D}

Dpto. Docencia INERAM

Introducción: El Rhodoccocus equii es un bacilo grampositivo pleomórfico, intracelular que compromete fundamentalmente a individuos con inmunocompromiso. Describimos aquí el primer caso visto en nuestra institución. Relato del caso: Varón de 49 años portador de anemia hemolítica por nueve años tratado con corticoides, azatioprina y ácido fólico, consulta por cuadro catarral de cinco meses de evolución, sensación febril y dificultad respiratoria. Es tratado con múltiples esquemas antibióticos sin respuesta, evolucionando la disnea hasta reposo, por lo que consulta a hospital de referencia. Posterior a endoscopia respiratoria que no arroja resultados diagnósticos se realiza pleuroscopia. Serología para HIV negativa. Durante su hospitalización desarrolla tumor renitente (absceso) submastoideo derecho que se punza. Los cultivos del líquido pleural y del absceso informan Rhodococcus. Se inicia vancomicina más ciprofloxacina, constatando buena evolución con este esquema terapéutico. Discusión: La mayoría de los casos publicados se describen en pacientes con HIV. También han sido reportados en pacientes sometidos a trasplantes de órganos, insuficientes renales crónicos, alcohólicos y usuarios de corticosteroides o ciclosporina. En el caso expuesto, adquiere preponderancia el consumo de corticoides y azatioprina, ambos medicamentos inmunosupresores. En individuos inmunocompetentes se han reportado a la fecha alrededor de veinticinco casos. La mortalidad asociada a la infección varía según la condición del hospedero, siendo de aproximadamente $11 \%$ en inmunocompetentes, $20-25 \%$ en pacientes inmunodeprimidos no-VIH y hasta 50-55\% en pacientes con SIDA. El caso aquí presentado tuvo una evolución favorable.

\section{7}

\section{Histoplasmosis diseminada y compromiso adrenal bilateral}

\section{Rolin P, Villalba F, Lemir R, Fusillo J,} Benítez S, Pérez D

\section{Dpto. Docencia INERAM}

Introducción: El Paraguay es considerado área endémica de histoplasmosis. El compromiso suprarrenal en el contexto de la micosis diseminada suele ser unilateral. Describimos un caso de presentación inusual en un paciente con serología negativa para HIV. Relato de caso: Paciente de sexo masculino de 79 años, que residió en el Chaco Paraguayo en el último año, sin comorbilidades aparentes que consulta por cuadro de ocho meses de tos productiva y pérdida de peso. Seis meses antes presentó fiebre preferentemente nocturna, más sudoración y escalofríos. Se percata de cambios en la coloración de la piel (oscurecimiento uniforme). Percibe tumoración pequeña en región cervical. Cinco meses antes: hemoptisis y aumento de masa cervical. Se realiza punción transtorácica de masa mediastinal: proceso granulomatoso inflamatorio necrotizante y necrosis central con células multinucleadas. Ante la no mejoría después de tratamiento antibacilar (paciente ingresa a UCIA con franca insuficiencia adrenal), se replantea nueva punción, cuyo material muestra regular cantidad de esporos micóticos con características típicas de Histoplasma capsulatum. Se inicia tratamiento con anfotericina B liposomal con mejoría progresiva y normalización de niveles de cortisol a lo largo del follow up. Discusión: El compromiso bilateral y la concomitancia de insuficiencia adrenal son entidades raras en el contexto de la histoplasmosis diseminada. El diagnóstico diferencial debe contemplar la posibilidad de tuberculosis, malignidades, sarcoidosis y linfomas dentro del contexto: ganglios mediastinales y masa adrenal.

\section{8}

\section{Sarcoma de Kaposi e insuficiencia respiratoria: reporte de 2 casos}

\section{Rolon L, Rolon R, Pavetti F, Rodríguez $S$}

\section{Dpto. Docencia INERAM}

Introducción: El sarcoma de Kaposi es un tumor mesenquimal de bajo grado que compromete a los vasos sanguíneos y linfáticos. El compromiso pulmonar suele darse en $45 \%$ de los casos. Presentamos dos casos vistos en un hospital de referencia. Descripción de los casos: Caso 1: Varón, 34 años, fumador y etilista. Cuadro con tos y hemoptisis leve, sensación febril nocturna, sudoración, decaimiento general y chillido de pecho, disnea a moderados esfuerzos, pérdida de peso, lesiones en mucosa oral y en piel con centro oscuro y nodular, indoloro, no pruriginosos, abarcando mayor extensión en parte inferior de piernas Laboratorio: leucocitosis, plaquetopenia, trombocitopenia moderada. Rx. tórax con patrón alvéolo nodular bilateral. Test Western-Blot (+). Biopsia de piel: sarcoma de Kaposi. No recibió TARVA. Óbito a las 48 horas de internación por insuficiencia respiratoria aguda tipo II. Caso 2: Varón de 48 años, 
que refiere tos seca y disnea de tres meses de evolución. Dolor mucosa paladar duro y disfonía un mes antes de consulta. Disnea progresa a reposo. FR: 28 x min. Lesión macular violácea paladar duro y poliadenopatías cervicales. Soplo tubárico campo medio derecho. Hgb: $10 \mathrm{~g} \%$, creat; 1.6 mg.dL.Rx: velam mitad ht derecho. Patrón hiliar y reticular controlateral basal. TAC tórax: opacidades difusas, broncograma aéreo língula. Broncoscopia: nódulos BFI. Bx ganglionar: sarcoma de Kaposi. Western-blot (+). Discusión: En varias series de decenas de pacientes, el diagnóstico de Kaposi pulmonar es sostenido por biopsia cutánea o ganglionar, como se dieron en los casos aquí discutidos. El compromiso mucocutáneo está presente en $85 \%$ de los casos de Kaposi pulmonar asociado a HIV y ésta es la razón por la que creemos que, en los casos presentados aquí, el compromiso tumoral es una gran probabilidad, no pudiendo descartar infecciones oportunistas.

\section{9}

Tuberculosis pleural: Características clínicas y manejo

Silguero N, Benítez S, Claure $C$, Benítez W, Gómez R, Pérez D, Gutiérrez I, Guggiari R, Rojas T

Dpto. Docencia INERAM

Introducción: Estudio de las características clínicas de pacientes internados por el diagnóstico de derrame pleural tuberculoso (DPT). Material y métodos: Estudio observacional descriptivo de registros clínicos de pacientes adultos con el Dx anatomopatológico de pleuritis granulomatosa y respuesta a tratamiento antibacilar, internados entre el 1 enero 2008 y 30 de junio de 2014. Se analizarán frecuencias y desenlaces en relación a una cohorte retrospectiva. Las variables cualitativas se expresan en frecuencias y las cuantitativas en medias \pm desvío estándar. Resultados: Se incluyeron 100 fichas de pacientes con edad $38 \pm 15$ años, (80 varones), con una edad de $36 \pm 16$ años; Comorbilidades prevalentes: tabaquismo (41\%), etilismo (15\%), neumopatías (8\%), cardiopatías (3\%), atb previo (65\%). Clínica: queja principal: disnea $(71 \%)$ dolor torácico (77\%); duración de síntomas: promedio $6.4 \pm 6$ semanas; síntomas: tos (55\%), expectoración (36\%), sensación febril (67\%), sudoración nocturna (35\%), pérdida de peso (36\%), astenia y anorexia (36\%). Signos vitales: FR: $23 \pm 3$ x min, FC $92 \pm 9 \times$ min, Pas:118 \pm 6 torr, PAd78 \pm 6 torr, temperatura axilar: $36.9 \pm 0.9^{\circ} \mathrm{C}$. laboratorio: Hgb:11.8 \pm 2 g \%, Hto:36 \pm $6 \mathrm{~mm}$, leucocitos $7,389 / \mathrm{mm}^{3}$, neutrófilos: $1 \pm 0.9 \%$, VSG1h: $68 \pm 13 \mathrm{~mm}$, glicemia: $108 \pm 6$ g \%, test rápido para VIH 5\% reactivo, $R x$. tórax: Preferencial compromiso unilateral y en $28 \%$ velamiento $\mathrm{SCF} \pm$ infiltrado del parénquima pulmonar, $85 \%$ tenían tamaño $>1 / 2$ hemitórax. Análisis líquido pleural: ph $7.45 \pm 0.8$, proteínas $5.13 \pm 0.8$ g \%, glucosa: $77 \pm 8$ g \%, $\mathrm{LDH}$ $1018 \pm 24$ UI, leucocitos 2,835/mm ${ }^{3}$, MN $80.5 \%$. En 5\% de los casos se constataron $>70 \%$ PMN, Diagnóstico: Tiempo desde ingreso: $5.4 \pm$ días, eficacia 1era. biopsia pleural: $72 \%$, baciloscopia positiva en esputo $11 \%$. Tto: tiempo desde ingreso: $7 \pm 3$ días, esquema utilizado categoría I, corticoides 9\%. Evolución intrahospitalaria: días de internación: $17 \pm 6$ días, fallecimiento $(0 \%)$. En relación a 65 pacientes con TB pleural (2004) existen diferencias significativas $(\mathrm{p}<0.05)$ en eficacia diagnóstica de primera biopsia (cohorte 2004:89\%); días de internación (2004: $32 \pm 19$ d) y en uso de corticoides (2004:17\%). Discusión: Se han mejorado algunos aspectos del manejo de la tuberculosis pleural, lo que implica reducción de costos. Se debe consignar que no disponemos rutinariamente de ADA en el servicio. Su implementación, ya rutinaria en varios países, impacta de mejor manera que el uso de la biología molecular.

\section{0}

\section{Evaluación de la CVF y del $\mathrm{VEF}_{1}$ en pacientes con obesidad clase III}
Silguero N, Benítez S, Sosa L, Fusillo J, Silvero G, Lo M, Maldonado L, Pérez D

Dpto. Docencia INERAM
Introducción: Si bien existe una mayor prevalencia de asma en la obesidad, no ocurre lo mismo para la limitación al flujo aéreo espiratorio (LFAE). Con el objetivo de estudiar esta asociación, elaboramos el siguiente estudio. Material y métodos: Estudio observacional de corte transverso de muestras por conveniencia. Se estudiaron antecedentes de tabaquismo, asma bronquial, síntomas relacionados y ocupación en una población de pacientes del sexo femenino con IMC $>40$ (obesidad tipo III). Se midieron variables antropométricas (edad, peso, altura, IMC y el índice cintura-cadera). A todos los pacientes se les efectuó prueba espirométrica estándar (Easy On-PC, ndd $\left.^{\circledR}\right)$, según normas y ecuaciones (Hankinson) estándares. Resultados: Treinta pacientes con obesidad mórbida, con promedios de edad $42.3 \pm$ 11.5 años (ds), $158.4 \pm 6.33 \mathrm{~cm}$ de altura, $124.7 \pm 6.33 \mathrm{~kg}$, IMC $49.7 \pm 17.8 \mathrm{~kg} / \mathrm{cm}^{2} \mathrm{y}$ relación cadera cintura $96.4 \pm 3.2$, fueron incluidos. Tabaquismo actual o antecedentes se consignaron en 10 pacientes y asma o síntomas relacionados se consignaron en 8. Espirometrías: dos casos de obstrucción leve se encontraron. Al análisis del ajuste de las variables (CVF y $\mathrm{VEF}_{1}$ ) a la ecuación de Hankinson, se encontró que en tres subgrupos analizados (tabaquistas, asmáticos y los no tabaquistas ni asmáticos), el error estándar (promedio de la diferencia observado-esperado) de la CVF siempre fue superior al de $\mathrm{VEF}_{1}$. Así, en tabaquistas: DCVF-250 mL y $\mathrm{DVEF}_{1} 230 \mathrm{~mL}$; en asmáticos DCVF $390 \mathrm{~mL}$ y $\mathrm{DVEF}_{1}-280 \mathrm{~mL}$ y en no tabaquistas ni asmáticos DCVF -230 mL y $\mathrm{DVEF}_{1}-160 \mathrm{~mL}$. ANOVA: $\mathrm{p}>0.05$. Discusión: Aunque no existen diferencias significativas probablemente debido al tamaño de los subgrupos, la obesidad extrema podría afectar en proporción mayor a la capacidad vital forzada que al $\mathrm{VEF}_{1}$ Por lo que la obesidad se podría asociar a un incremento en la tasa $\mathrm{VEF}_{1} /$ $\mathrm{CV}$, lo que indefectiblemente levanta el umbral de discriminación de los trastornos obstructivos diagnosticados por espirometría.

\section{1}

Silicosis en el Paraguay: Estudio observacional 
Silguero N, Campuzano D, Ojeda M, Paiva F, Pérez $D$

Dpto. Docencia INERAM

Introducción: La silicosis es una neumoconiosis fibrosante y progresiva que resulta de la inhalación de sílice cristalina. Existen dos reportes nacionales previos: 200 casos (1950-1980) y 74 casos (20002003). Con el objetivo de evaluar las características clínicas y los desenlaces de la hospitalización en hospital de referencia, describimos esta serie. Material y métodos: Estudio observacional de los registros médicos de pacientes internados en nuestro servicio entre noviembre 2009 a noviembre 2013. Se incluyeron pacientes con diagnóstico de silicosis. Se consignan datos demográficos y ocupacionales, clínicos y evolutivos. Las variables se expresan en medidas de tendencia central y de dispersión. Breve comparación de algunas características determinadas con otras de la cohorte 2000-2003. Resultados: Se incluyeron 45 fichas médicas de pacientes del sexo masculino con edad promedio de $53 \pm 13$ años (ds). Lugar de procedencia: Departamento Central (n = 18); Cordillera (13) y San Pedro (8): Los otros departamentos presentaban 2 o menos casos. Ocupación: picapedreros (50\%), cavadores de pozo $(46 \%)$ y oleros (2\%). Todos referían larga data en sus ocupaciones y ninguna protección durante su labor. Comorbilidades: tabaquismo (31\%); hipertensión arterial (22\%) y diabetes mellitus (4\%). Neumopatías concomitantes: tuberculosis $(\mathrm{n}=12)$; neumotórax $(\mathrm{n}=$ 7); cáncer broncogénico epidermoide o escamoso $(n=1)$. Motivo de consulta: empeoramiento de disnea (100\%). Síntomas: tos y disnea $(100 \%)$, fiebre $(40 \%)$, expectoración $(35 \%)$, dolor torácico (31\%), chillido de pecho $(17 \%)$. Internaciones anteriores por cuadro similar: $37 \%$. El diagnóstico se fundamentó en la historia clínica, historia ocupacional y hallazgo radiológico. Mortalidad intrahospitalaria $=8(17.7 \%)$. En comparación con la cohorte 200-2003 se observó diferencia significativa $(\mathrm{p}<0.01)$ en la proporción picapedreros/cavadores de pozos, constatando una disminución de prevalencia de cavadores de pozo en esta serie. Discusión: A diferencia de otros países donde las causas de esta enferme- dad devienen de actividades de minería o de las industrias, las consignadas aquí son de origen ocupacional más elemental. En esta cohorte se constata una disminución importante de cavadores de pozos como causa, permaneciendo la mortalidad intrahospitalaria constante (17.7\%).

\section{2}

\section{Lesiones traqueales} focales: A propósito de un caso

\section{Sotelo F, Ayala J, García A, Colombo $C$, et al.}

Hospital Alta Complejidad “JD Perón” (Formosa-Argentina)

Introducción: Los tumores primitivos de traquea son infrecuentes y el éxito del tratamiento quirúrgico depende de la precisa indicación y selección del paciente. Propósito: Demostrar que un tratamiento multidisciplinario puede contribuir a mejorar la calidad de vida en pacientes que padecen PAP. Caso clínico: Mujer de 59 años, ex tbq 40 p/y, reside, dislipidémica y diagnóstico reciente de asma. Tratamiento habitual fluticasona/salmeterol 1000/100 ug/día. MC: episodios de bronquitis recurrente asociado a disnea CF II. 1) Rx. tórax (mayo 2011): signos de atrapamiento aéreo; 2) Espirometría (mayo/2012): FVC 3.57 1005\%); $\mathrm{FEV}_{1}: 1.89$ (78\%); $\mathrm{FEV}_{1}$ / FVC: 64; PEF: (70\%) alteración de morfología curva flujo/volumen; 3) Colagenograma: Negativo; 4) VIH: No reactivo. Por no mejoría sintomática con terapéutica instaurada y espirometría anormal se solicita Tc Tórax (enero 2012) hallazgo de ocupación de la luz de vía aérea central por formación tumural de $20 \times 20 \mathrm{~mm}$ de diámetro, por lo que se realiza fibrobroncoscopia exploradora con la consiguiente broncoscopia rígida terapéutica: Se aplica terapia de radiofrecuencia, y exéresis del tumor por resección mecánica con broncoscopio rígido, repermeabilizando la vía aérea. Anatomía patológica: macroscopia: tumor de $20 \times 20 \mathrm{~mm}$ diámetro, microscopia: lesión hamartomatosa tapizada por epitelio respiratorio, constituida por cartílago, tejido adiposo, múltiples quistes de diversos tamaños, con proyecciones papilares luminales. Dx: Hamartoma traqueal con aéreas de adenoma papilar. Espirometría control postexéresis con morfología curva flujo/volumen normal. Conclusión: La poca especificidad de los síntomas simula otras enfermedades de origen respiratorio, más frecuentemente tratadas como asmáticas y se deben considerar como diagnóstico diferencial en el asma difícil de controlar. La espirometría continúa siendo una herramienta de gran utilidad para los diagnósticos diferenciales. Los tumores primarios benignos raros de vía aérea central incluyen hamartoma.

\section{3 Evaluación neumológica de usuarios de drogas ilícitas}

Vigo E, Benítez S, Fusillo J, Orrego A, Fresco M, Aranda D, Pérez D

Dpto. Docencia INERAM-Centro Adicciones MSPyBS

Introducción: Los efectos clínicos y funcionales de las drogas ilícitas son controversiales a diferencia de lo conocido acerca del tabaco. Con el objetivo de estudiar la sintomatología y la función pulmonar en usuarios de estas sustancias, hemos diseñado este trabajo. Material y métodos: Estudio observacional de una muestra por conveniencia. De centro de referencia se seleccionaron individuos con historial de uso y se excluyeron pacientes con conocidas enfermedades respiratorias (asma, EPOC, secuela de TB, fibrosis quística; se aplicó cuestionario estructurado y se realizó prueba espirométrica con prueba broncodilatadora (Easy OnPC, ndd $^{\circledR}$ ), utilizándose las ecuaciones de Hankinson. Se firmó un consentimiento informado donde se garantiza anonimato. Se realiza un análisis descriptivo de las variables encontradas. Resultados: 25 individuos fueron incluidos (3 mujeres) con una edad promedio de $16 \pm 6.23$ (ds) años, $159 \pm 14.1 \mathrm{~cm}$ y $54 \pm 16 \mathrm{~kg}$. Hábitos tóxicos: marihuana (88\%), crack (64\%) y cocaína (48\%), además de tabaco (96\%) y alcohol (84\%).Evaluación: el 68\% (17) refería tos, 36\%(9) disnea y 24\%(6) sibilancias. Al analizar las pruebas es- 
pirométricas efectuadas (GLI, 2012) se consignan $24 \%$ de patrones obstructivos y en $28 \%$ se constataron variaciones $>12 \%$ después de 400ug de salbutamol. Llamó poderosamente la atención la presencia de flujos supranormales $\left(\mathrm{VEF}_{1}>100 \%\right)$ que no disminuyeron después de broncodilatadores. Discusión: La muestra estudiada aquí denota un «overlap» o superposición importante de dependencia a tóxicos que hacen imposible derivar una tendencia asociativa única. Cabe resaltar el promedio de edad de la muestra y sobre todo el hallazgo de importante frecuencia de síntomas respiratorios junto a una tasa no despreciable de alteraciones obstructivas. El uso «pesado» de marihuana está asociado a enfermedad obstructiva, así como el uso importante de crack. Ya que los factores de confusión no pueden ser eliminados, como suele suceder en muestras poblacionales reales, no es permitido postular: a) la presencia de enfermedad obstructiva previa sin diagnóstico en la muestra, o b) el rápido desarrollo de problemas respiratorios, impulsados por una sinergia de sustancias con el tabaquismo.

\section{4}

\section{Mujer adulta no fumadora con adenocarcinoma pulmonar con infiltración difusa}

\section{Virgili G, Arévalos V, Espinoza G, Vera J}

\section{Instituto Previsión Social}

Introducción: El carcinoma de pulmón es la principal causa de muerte por cáncer en el mundo. Aunque es sabido que esta neoplasia se asocia en la mayoría de los casos con el consumo de tabaco, en un $15 \%$ afecta a personas no fumadoras, la mayoría de ellas mujeres, sin conocerse la explicación de esta diferencia por sexos. Descripción del caso: Paciente de sexo femenino, 46 años, no tabaquista, sin patología de base, que consulta por cuadro de un mes de evolución de tos seca, persistente, acompañada desde el inicio de dificultad respiratoria provocada por esfuerzos moderados que progresa hasta el reposo. Recibió al principio antibióticos por vía oral (amoxicilina sulbactam), expectorantes y antitusivos, sin mejoría. Ingresa a centro asistencial recibiendo antibióticos endovenosos (ceftriaxona más levofloxacina), persiste cuadro y es derivada a IPS central. Al ingreso, al examen físico se destaca sibilancias bilaterales a la auscultación, se inicia tratamiento con claritromicina, añadiéndose corticoides endovenosos y nebulización con escasa mejoría. TAC informa infiltrado pulmonar mixto en vidrio esmerilado difuso con componente nodular mixto en bases. Se realiza fibrobroncoscopia con toma biopsia, informándose adenocarcinoma infiltrante moderadamente diferenciado. Se solicita estudio de la muestra de biopsia para EGFR, y se esperan los resultados para toma de conducta. Discusión: El adenocarcinoma pulmonar últimamente ha desplazado al escamoso como el más frecuente, pudiendo tener diferentes tipos de presentación, ya sea clínicamente como a nivel radiológico. Además de la presentación con síntomas inespecíficos se suma la imagen poco evocadora de adenocarcinoma, debido a la Infiltración difusa en forma bilateral. Se justificaba en este caso el estudio para orientar el tratamiento probable con erlotinib dirigido a la inhibición de la cinasa de EGFR.

\section{5}

\section{Sarcoidosis: Serie de casos}

Rodríguez S, Yegros B, Cárdenas $S$, Fusillo J, Arbo G, Lemir R, Pérez D

Dpto. Docencia INERAM-Hospital Clínicas

Introducción: La sarcoidosis es una enfermedad granulomatosa sistémica de causa desconocida que frecuentemente compromete al pulmón. Presentamos una serie de casos. Material y métodos: Estudio observacional de casos consecutivos vistos en varios servicios neumológicos de nuestro país en período comprendido entre 1999 y 2013. Criterio de inclusión: histopatología compatible con sarcoidosis y exclusión de otras enfermedades. Se consignan las variables clínicas e imagenológicas de presentación. Resultados:
Se encontraron 12 casos confirmados con biopsia. Del total de pacientes, 7 eran de sexo femenino. La edad promedio de la muestra era de 44 años (rango: 29-59 años). El 40\% tenía > 50 años. Tres de ellos presentaban comorbilidades (2 HTA y 1 obesidad mórbida). El 50\% (6) consultó por disnea y el resto ya sea por tos, dolor, hemoptisis o artralgias. La duración de los síntomas antes de la consulta fue extremadamente variable con rango de 7 días a 3 años, excluyendo el único caso de pulmón fibrótico (estadio IV): 10 años. La distribución de la frecuencia según estadios fue: estadio I: 2 (dos); estadio II: 8 (ocho); estadio III: 1(uno); estadio IV: 1(uno). El espectro de presentación es variable ya que también están consignados un caso de sarcoidosis e hipertensión pulmonar y otro de sarcoidosis quística. La biopsia transbronquial se utilizó en 5 casos, en 3 la mediastinoscopia y en 2 la toracotomía. La biopsia de piel dio el diagnóstico en dos casos. Discusión: Aunque la literatura refiere que la sarcoidosis se presenta antes de los 50 años; en esta serie, un porcentaje importante denota $>50$ años. La presentación típica suele ser como tos no productiva, disnea y a veces chillido. Uno de los casos aquí se presentó con hemoptisis, evento infrecuente. Llama la atención el escaso uso de la mediastinoscopia para el diagnóstico. Hace falta un estudio multicéntrico para ajustar y uniformizar los registros clínicos al seguimiento de los pacientes.

\section{6}

\section{Neumonía actinomicótica}

Estigarribia Avalos LC, Calderoli $F$, Hasin G, Rodríguez Andersen C, Arce Aranda $C$, Estigarribia Olmedo LC

Cátedra Neumología-Hospital Clínicas-FCMUNA

Introducción: La actinomicosis es una enfermedad infecciosa crónica, por lo general, causada por un bacilo, ramificado, filamentoso, anaerobio, grampositivo: Actinomyces israelii; se caracteriza por supuración y formación de fístulas por las que drena pus con gránulos blanco amarillentos. Puede provocar compromiso cérvico-facial (55\%), abdomino-pélvico 
(20\%), torácico (15\%) y de múltiples órganos (10\%), incluyendo piel, cerebro, pericardio y extremidades. La actinomicosis pulmonar afecta a todas las edades, y a veces con una distribución bimodal, que abarca entre 11 y 20 años, así como a $\operatorname{los} 40$ y 50 años. La incidencia de infección es de 2 a 4 veces mayor en los varones en comparación con las mujeres. Caso clínico: S.M., femenino, 54 años. Procedencia: San Lorenzo - Paraguay. Antecedentes: cinco meses de tos con expectoración hemoptoica de escasa cantidad que con el transcurrir del tiempo aumenta la frecuencia; niega sensación febril, disnea o dolor torácico. Pérdida de 18 kilos aproximadamente desde el inicio de los síntomas. Hemograma: GB: 8610 Hb: 12.1 Hto: 36.3 Radiografía de tórax: Normal, TAC de tórax: muestra una opacificación heterogénea en región posterior e inferior derecha. Tres frotis para BAAR con resultado negativo; se realiza fibrobroncoscopia con toma de 6 muestras sin complicaciones con anatomía patológica normal. Ante la sospecha de proceso neoplásico se realiza una toracotomía con lobectomía inferior derecha, vaciamiento ganglionar mediastinal con drenaje pleural sellado bajo agua. Diagnóstico anatomopatológico del lóbulo inferior de pulmón derecho: Neumonía actinomicótica abscedada. El tratamiento fue la combinación del desbridamiento quirúrgico y la administración prolongada de ampicilina Iv por 10 días. Comentarios: El caso de esta paciente no produjo fístula para drenar la supuración pulmonar, siendo de larga evolución. - Se debe sospechar la existencia de un foco sin drenaje en los pacientes que no responden al tratamiento prolongado (de 4 a 12 meses). —-Se planteó una discusión en la elección del antibiótico post-lobectomía.

\section{7}

\section{Paracoccidioidomicosis diseminada crónica con derrame pleural}

\section{Estigarribia Avalos LC, Calderoli F, Hasin G, Rodríguez Andersen C, Estigarribia Olmedo LC}

Cátedra Neumología-Hospital ClínicasFCMUNA
Introducción: La paracoccidioidomicosis es una micosis granulomatosa y supurativa, de evolución subaguda o crónica y de pronóstico grave producida por un hongo difásico, el Paracoccidioides brasiliensis. Es endémica en una amplia zona tropical y subtropical boscosa y húmeda de América del Sur y Central, desde el centro de México norte hasta el paralelo $32^{\circ}$ de latitud sur en la Argentina y el Uruguay. Cursa con afectación pulmonar, lesiones cutáneas y de la mucosa oral. El diagnóstico se basa en la demostración de levaduras con gemación múltiple («ruedas en timón»). Caso clínico: C.C. masculino, 30 años, procedencia: Borja - Guaira - Paraguay. Antecedentes: 2 meses antes del ingreso presenta lesiones pápulo-eritematosas en comisuras labiales y ala nasal derecha, al cuadro se agrega dificultad respiratoria a moderados esfuerzos que no cede con el reposo, es tratado con claritromicina 1 g/día por 7 días y aciclovir crema; al no ceder el cuadro acude a nuestro servicio. Radiografía de tórax: en donde se observa derrame pleural severo izquierdo; se realiza toracocentesis diagnóstica y cuyo resultado fue exudado mononuclear ( $85 \%$ ); examen directo de raspado de paladar duro en donde se observan levaduras con exoesporulación con características morfológicas de Paracoccidioides brasiliensis. Se biopsia ganglio axilar izquierdo y anatomía patológica informa: Proceso inflamatorio crónico granulomatoso: Paracoccidioidomicosis; se colocó tubo de drenaje pleural sellado bajo agua con un débito total en los días de internación de $9,870 \mathrm{~cm}^{3}$ de líquido serohemático; se realizaron 3 frotis y cultivo de líquido pleural para BAAR en donde los resultados fueron negativos. Conclusión: $\mathrm{La}$ importancia de este caso fue que el derrame pleural izquierdo que presentó fue severo, y que en las bibliografías consultadas, tanto nacionales como extranjeras, no cita al derrame pleural como signo-sintomatología. El tratamiento fue de itraconazol $400 \mathrm{mg}$ / día por la agresividad del cuadro el primer mes y luego 5 meses de 100 mg/día.

58

Costos de hospitalización de la neumonía adquirida en la comunidad
Molinas G, Fusillo J, Flores L, Pérez D

Dpto. Docencia INERAM

Introducción: Existen escasos trabajos nacionales sobre farmacoeconomía de enfermedades prevalentes. El objetivo de este estudio fue investigar los costos de la hospitalización de la neumonía adquirida en la comunidad (NAC) en un servicio de referencia. Material y métodos: Estudio observacional de corte transverso sobre costes directos de recursos de diagnóstico y aspectos farmacológicos del tratamiento de los casos de NAC vistos durante el año 2013. El análisis de costes directos incluyó: a) coste estancia: (calculado multiplicando número de días de hospitalización por coste estancia/día). El coste de las pruebas microbiológicas, bioquímicas y radiológicas se han incluido; b) coste de tratamiento farmacológico (PVF), diferenciando los ítems derivados de antibioticoterapia o broncodilatadores inhalados. La medida de la efectividad fue dada por el alta hospitalaria. Los costes fueron extraídos de la base de datos del MSPyBS (pliegues de bases y condiciones para licitación de medicamentos). Resultados: Del total de internados $(2,081)$, $4.5 \%(\mathrm{n}=100)$ cumplieron los criterios de inclusión. Demografía: $51 \%$ masculinos, edad promedio $57.2 \pm 20$ años (ds). Apenas el $20 \%$ de la muestra no refirió comorbilidades). Tiempo promedio de internación (días) $10.2 \pm 6.6$ (ds). Costo total anual: G 179.934.370 (\$39.985); G 223.529 (\$49.6) por día. El cálculo por paciente $=\mathrm{G} 815.882$ (\$181); costos de imágenes corresponden al 26.7\% (\$10.692); el tratamiento antibiótico $45.3 \%$ (\$18.130); costos de laboratorio: $18.5 \%$ (\$7.388); costo de aerosoles y nebulizaciones $12.5 \%$ (\$974). Complicaciones: 20\% (19 derrame pleural; un caso con empiema); Desenlaces: Óbito $10 \%$, traslado UCIA: $12 \%$, alta $78 \%$.

Discusión: Los costes directos de la NAC/ paciente son variables en diferentes países (\$1.409 en Alemania o \$836 en Brasil) y esto se debe a muchos factores. Un estudio reciente en el INERAM demuestra que los costes directos de la internación de los EPOC son de \$575/día. Es interesante resaltar que el tratamiento antibiótico impacta en $45 \%$ de costes totales. Sería 
interesante realizar comparaciones entre esquemas de antibióticos protocolizados e incluir también el seguimiento de pacientes complicados para ajustar los análisis.

\section{9}

\section{Aspectos relevantes sobre el biomonitoreo de la concentración de metales pesados del aire ambiente en Asunción-Paraguay}

\section{Coronel R, Fretes J, Cañiza B, Rodríguez M, Vigo E, Pérez D}

Dpto. Docencia INERAM

Introducción: Elaboramos el presente estudio para evaluar la concentración ambiental de plomo, cadmio, mercurio y arsénico en especies autóctonas de musgos expuestas durante un período a ambiente urbano y analizar algunos aspectos metodológicos del biomonitoreo en nuestro país. Material y métodos: En un estudio observacional se obtuvieron muestras de musgos del Cerro Patiño (37 km de Asunción) para trasplantarlas en cinco sitios de alto tráfico vehicular en la Ciudad de Asunción. Una de las muestras se tomó como control. Las muestras quedaron a la intemperie durante 50 días (9 septiembre 2013-24 octubre 2013) para luego recolectarlas y someterlas a estudio mediante la técnica de espectrometría de masas con fuente de plasma de acoplamiento inductivo. Se caracterizaron los briofitos y se consignaron todas las variables climatológicas acontecidas durante el período de estudio. Se requirió una segunda fase de toma de muestra de musgo control (control 2). Resultados: Después de 50 días de exposición se encontraron niveles de plomo con rango 0.009 a $0.039 \mathrm{mg} / \mathrm{kp}$ (muestras control: 0.008 y $0.021 \mathrm{mg} / \mathrm{kg}$ ) y también niveles de arsénico con rango entre 0.006$0.028 \mathrm{mg} / \mathrm{kp}$ (muestras control: 0.017$0.056 \mathrm{mg} / \mathrm{kg}$ ). Los briofitos empleados pertenecían a dos familias: Hypnaceae y pilotrichaceae. El rango de temperatura, humedad relativa, viento y precipitaciones no alcanzó niveles extremos durante el ciclo estudiado. Discusión: Se detectan niveles discretos de plomo y arsénico en

las muestras aquí estudiadas y que podrían representar a las zonas estudiadas, aunque se hacen necesarias otras investigaciones sobre variación dentro y entre las especies de musgos de nuestro país.

60

Impacto de la polución del aire en agentes de tránsito de la Ciudad de Asunción

\section{Arruabarrena R, Bogarin $P$, Pérez $D$}

Dpto. Docencia INERAM

Introducción: No existen estudios en nuestro país sobre el impacto de la contaminación ambiental en personal altamente expuesto. Con el propósito de describir las potenciales alteraciones clínicas, funcionales y analíticas hemos elaborado el presente trabajo. Material y métodos: Estudio observacional, transversal en el que se evaluó a trabajadores con exposición a polución ambiental por más de 8 horas diarias en un período no menor a 2 años. Se describen las características de una muestra probabilística de policías de tránsito vial de la Ciudad de Asunción con funciones operativas del área metropolitana. Con el objetivo de comparar las variables, se analizó otra muestra de personas con residencia y trabajo rural. Se realizó un cuestionario de síntomas respiratorios, exámenes de laboratorio, radiografía de tórax, espirometría y medición de la concentración sérica de plomo. Resultados: Se incluyeron en el estudio a diez agentes de tránsito (los de mayor antigüedad) y 5 peones de estancia. La prevalencia de síntomas respiratorios fue mayor en el grupo de agentes de tránsito. No hubo diferencias en las variables de función pulmonar, analítica, radiológica ni en las concentraciones séricas de plomo. Discusión: Existe amplia literatura sobre la mayor prevalencia de enfermedades y síntomas respiratorios en agentes de tránsito probablemente resultante de exposición a polución ambiental, como se ha consignado en este trabajo aún siendo la muestra pequeña. Mayor tasa de dislipidemia en el grupo de agentes estudiado. Los datos son erráticos al analizar los efectos funcionales de la polución. El promedio de concentración plúmbica en las muestras analizadas aquí se encuentra bajo el dintel tóxico establecido por organismos internacionales.

\section{1 \\ Evaluación de los costes del tratamiento de las agudizaciones de la EPOC}

Rolin $\boldsymbol{P}$, Jiménez $V$, Flores $L$, Pérez $D$

Dpto. Docencia INERAM

Introducción: La prevalencia de la enfermedad pulmonar obstructiva crónica (EPOC) se sitúa entre $7.8 \%$ y $19.7 \%$ en Latinoamérica (PLATINO). Debido a ello y a la creciente morbimortalidad asociada, esta patología podría generar un importante consumo de recursos sanitarios. Con el objetivo de determinar los costos directos en pacientes internados por el diagnóstico de agudización de EPOC en un hospital de referencia, hemos llevado a cabo el siguiente estudio. Material y métodos: Estudio observacional, transversal que consistió en análisis de registros clínicos de pacientes internados en un servicio de referencia por el diagnóstico de agudización de EPOC durante el período enero 2013 hasta diciembre 2013. El análisis de costes directos comprendió el cálculo $a$ ) coste total de internación: que incluyó el coste de las pruebas microbiológicas, hematológicas, bioquímicas, imágenes más los costos de tratamiento farmacológico y b) coste de tratamiento farmacológico total (expresado PVF): diferenciando también aquel derivado del tratamiento antibiótico y del uso de broncodilatadores inhalados. Resultados: Se estudiaron 135 casos de exacerbación de EPOC internados durante el año 2013. La media de días de internación fue de $12.9 \pm 11.05$ días. Los costos totales anuales corresponden a G 349.545.880 (77.676 \$), es decir, 575 \$S/paciente; donde los costos de imágenes y espirometría corresponden al $39.6 \%$ (30.766 \$); tratamiento antibiótico corresponden el $30.3 \%$ (23.558 \$); el costo de laboratorio $15.7 \%$ (12.229 \$); costo de aerosoles $12.5 \%$ (9777 \$) y el costo de 
oxígeno 1.7\% (1.344 \$). Conclusión: Los costes de las agudizaciones de EPOC en un centro de referencia en el Paraguay se proyectan como los más bajos de la región, aunque se imponen ajustes universales tanto a las definiciones e historia natural de la exacerbación de EPOC, como a los sistemas de salud en los cuales se realizan los análisis.

\section{2}

\section{Chlamydia pneumoniae y Mycoplasma pneumoniae: ¿Están ellos relacionados con crisis asmática severa?}

Iramain $\boldsymbol{R}$, Jara $A$, Spitters $C, D e$ Jesús R, Bogado N, Cardozo L

Cátedra Pediatría-Hospital Clínicas-FCMUNA

Introducción: Mycoplasma pneumoniae y Chlamydia pneumoniae son frecuentes agentes de enfermedades respiratorias agudas y han sido reconocidos como agentes infecciosos desencadenantes de asma. El objetivo de este trabajo fue investigar la frecuencia de estos agentes y su relación con asma severa. Material y métodos: Estudio prospectivo realizado en la Unidad de Urgencias entre enero 2007 y marzo del 2012. 82 pacientes fueron enrolados, de los cuales 55 tuvieron asma. Fueron divididos en 3 grupos: Grupo 1: 27 niños con asma severa; Grupo 2: 29 niños con asma estable, y Grupo 3: control 26 niños (niños sanos). Las muestras fueron procesadas por el método de IgM ELISA, y extraídas por aspiración nasal. Resultados: Edad media fue Grupo 1: $10.9 \pm 2.5$, Grupo 2: $10.1 \pm 2.9$ y Grupo 3: $10.9 \pm 1.9 \mathrm{p}=0.4$. M. pneumoniae: IgM fue observado $6 / 26$ $19.2 \%$ en el Grupo 1, 2/29 3.4\% en el Grupo 2 y 0/26 en el Grupo control ( $\mathrm{p}=$ 0.01). C. pneumoniae: IgM fue encontrado 7/26 26.9\% en el Grupo 1, 2/29 6.9\% en el Grupo 2, y 0/26 en los controles ( $\mathrm{p}=$ 0.005). Ninguna significancia estadística fue encontrada entre el grupo asma estable y grupo control. Conclusiones: $M$. pneumoniae y $C$. pneumoniae pueden jugar un rol en el desarrollo de asma severa.

\section{3}

\section{Tratamiento con solución salina hipertónica en lactantes hospitalizados con bronquiolitis aguda}

Iramain R, Jara A, Coronel J, Cardozo L, Bogado N, Chirico C, Morinigo R, Palomar $S$

Hospital de Clínicas-Cátedra de Pediatría-Hospital Barrio Obrero-Instituto Privado del Niño

Introducción: El edema de las vías aéreas y las secreciones mucosas son características patológicas predominantes en lactantes con bronquiolitis aguda (BA). La nebulización con solución salina hipertónica al 3\% (SSH) puede reducir los cambios patológicos y disminuir la obs- trucción de la vía aérea. Los mecanismos de acción postulados para la SSH son los siguientes: 1) Induce un flujo osmótico de agua dentro de la capa mucosa, rehidratando la superficie líquida de la vía aérea y mejora el clearance mucoso. 2) Rompe las bandas iónicas dentro del gel mucoso; por lo tanto, reduce la viscosidad y la elasticidad de la secreción mucosa. Objetivos: primarios son: 1) Disminución de los días de internación de los lactantes comparado con un grupo control que recibirá terapia estándar más solución salina normal (SSN). 2) La mejoría en el score clínico (SC) secundarios son: 1) La disminución del requerimiento de $\mathrm{O}_{2}$, y 2) La mejoría de la oxigenación (Sat.O ${ }_{2}$ ). Material y métodos: Un total de 106 pacientes (edad media de $5.1 \pm 6.4$ meses) (rango: 1-40 meses) fueron admitidos al hospital y reclutados para recibir tratamiento de BA, en tres hospitales, desde mayo del 2011 a julio del 2014. Fue un ensayo clínico, aleatorizado, controlado y a doble ciego. Divididos en 2 grupos para recibir SSH o SSN con epinefrina. Resultados: Los lactantes del grupo SSH han tenido importante disminución en los días de hospitalización $1.7 \pm 0.76$ vs. 4.9 \pm 2.3 del grupo SSN, p $<0.001$. El SC demostró mejoría significante en el grupo SSH comparando con el grupo SSN p < 0.001. El requerimiento de $\mathrm{O}_{2}$ de ambos grupos no fue diferente $\mathrm{p}=0.7$. La Sat. $\mathrm{O}_{2}$ al segundo día de internación fue similar en los 2 grupos $\mathrm{p}=0.8$. Conclusiones: $\mathrm{La}$ solución salina al 3\% con epinefrina es más efectiva que la solución salina normal en pacientes moderadamente severos con bronquiolitis aguda. 